\title{
Polyamide blend-based nanocomposites: A review
}

\author{
W. S. Chow ${ }^{1,2}$, Z. A. Mohd Ishak ${ }^{1,2 *}$ \\ ${ }^{1}$ School of Materials and Mineral Resources Engineering, Engineering Campus, Universiti Sains Malaysia, Nibong Tebal \\ 14300 Penang, Malaysia \\ ${ }^{2}$ Cluster for Polymer Composites, Science and Engineering Research Centre, Engineering Campus, Universiti Sains \\ Malaysia, Nibong Tebal 14300 Penang, Malaysia
}

Received 24 September 2014; accepted in revised form 26 November 2014

\begin{abstract}
Polymer blend nanocomposites have been considered as a stimulating route for creating a new type of high performance material that combines the advantages of polymer blends and the merits of polymer nanocomposites. In nanocomposites with multiphase matrices, the concept of using nanofillers to improve select properties (e.g., mechanical, thermal, chemical, etc) of a polymer blend, as well as to modify and stabilize the blend morphology has received a great deal of interest. This review reports recent advances in the field of polyamide (PA) blend-based nanocomposites. Emphasis is placed on the PA-rich blends produced by blending with other thermoplastics in the presence of nanofillers. The processing and properties of PA blend-based nanocomposites with nanofillers are discussed. In addition, the mechanical properties and morphology changes of PA blends with the incorporation of nanofillers are described. The issues of compatibility and toughening of PA blend nanocomposites are discussed, and current challenges are highlighted.
\end{abstract}

Keywords: polymer blends and alloys, nanocomposites, polymer composites

\section{Introduction}

\subsection{Background of polyamide blend-based nanocomposites}

Polyamide (PA) is well known as an engineering thermoplastic material that is widely used in industrial applications (e.g., fibers, films, textiles and various molding products) for its remarkable mechanical and thermal properties. However, these advantages are accompanied by limitations such as moisture absorption, notch sensitivity, relatively low impact strength and poor dimensional stability. Thus, modification of PA to improve its physical properties and to introduce new properties has drawn much attention [1-4]. Polymer nanocomposites offer new technological and economical benefits. The incorporation of nanometer-scale reinforcement may dramatically improve select properties of PA. These nanocomposites exhibit superior properties such as enhanced mechanical properties, reduced permeability, increased electrical conductivity and improved flame retardancy [5-9].

Recently, there has been increasing interest in blending a second polymeric component into PA nanocomposites with the addition of a nanofiller (e.g., nanoclay, nanotube). Blends of PA with polyolefins are particularly attractive because it is theoretically possible to couple the excellent mechanical properties of the PA and the good processability and toughness of the polyolefin. Nanocomposites based on polymer blends of PA and polyolefins are widely reported in the scientific literatures. For example, blending of polyamide 6 (PA6) and polypropylene (PP) has been attempted to achieve improvement in mechanical properties, paintability and barrier properties. PA6 contributes mechanical and thermal properties, whereas PP ensures good processability and

\footnotetext{
${ }^{*}$ Corresponding author, e-mail: zarifin@usm.my

(C) BME-PT
} 
insensitivity to moisture. Polymer blend nanocomposites may lead to a new type of high performance material that combines the advantages of polymer blends and the merits of polymer nanocomposites $[10,11]$.

Consequently, two types of PA blend-based nanocomposite have been studied by numerous researchers, i.e., PA nanocomposites prepared by thermoplastic-thermoplastic blending and rubber (both functionalized and un-functionalized) modification approaches:

(a) PA nanocomposites with a matrix composed of a blend of two thermoplastics (for example, PA6/PP/nanoclay [1, 12-18], PA6/polyimide/ organoclay [19]; PA6/thermotropic liquid crystalline polymer (TLCP)/organoclay [20]; Nylon 66/Nylon 6/organoclay [21]; PA6/acrylonitrile-butadiene-styrene (ABS)/multi-walled carbon nanotube (MWNT) [4, 22]; PA6/low density polyethylene (LDPE)/nanoclay [23]; PA6/LDPE/organoclay [24]; polyamide 12 (PA12)/PP/boehmite alumina nanoparticles [25]; PA6/polymethyl methacrylate (PMMA)/functionalized single-walled carbon nanotube (SWCNT) [26]; PA6/polystyrene (PS)/nanoclay [27]; PA6/PS/nanosilica [28])

(b) PA nanocomposites toughened by a rubber or rubber-modified PA6 nanocomposites (for example, PA6/maleated styrene-ethylene butylenestyrene (SEBS-g-MA)/montmorillonite [29]; PA6/maleinized ethylene-propylene-rubber (mEPR)/nanoclay [30]; PA6/ethylene-co-propylene maleated rubber/organoclay [31]; PA6/silicone rubber/clay [32]; PA66/SEBS-g-MA/organoclay [33]; PA6/metallocene ethylene-polypropylene-diene copolymer/maleated ethylenepolypropylene-diene copolymer (EPDM-g-MA)/ nanoclay [34]; PA6/maleinized ethylene propylene-diene monomer (mEPDM)/nanoclay [35]; PA6/maleinized styrene-ethylene-butylenestyrene (mSEBS)/nanoclay [36-38]; PA6/ maleated ethylene-propylene-diene rubber (EPDM-g-MA)/organoclay [39]; PA6/ethylene-co-butyl acrylate elastomer/nanotalc [40]; amorphous PA/ethylene-1-octene (EOR)/organoclay [41]; PA6/maleated styrene-hydrogenated butadiene-styrene (mSEBS) elastomer/nanosilica [42]; PA6/SEBS-g-MA/silicon carbide nanoparticles [43]; PA6/acrylonitrile butadiene rubber (NBR)/nanoclay [44]; PA6/ethylene- propylene-diene metallocene terpolymer (EPDM)/sepiolite [45]; PA6/reactive acrylonitrile-butadiene-styrene core-shell rubber (ABS$g$-MA)/organoclay [46]).

The first approach can be used to tailor select properties of the PA6 nanocomposites, such as the mechanical, thermal, and water barrier properties, by blending with other types of thermoplastics. The latter approach offers the potential to overcome the tendency for notch sensitivity and low notchedfracture toughness of PA nanocomposites by means of rubber modification. Table 1 lists examples of PA blend-based nanocomposites.

Polymer blends have been described as a well recognized class of materials with a set of properties targeted towards specific applications, and they have received a great deal of academic and technological interest. The properties of the blends are strongly influenced by the constituent blend components, the interface and the morphology developed during processing [22, 47]. Blending of existing polymers has become a widely accepted practice for obtaining new materials with desirable properties. Although some polymer blends are completely or partially miscible, most polymer blends are immiscible and exhibit multiple phase morphologies [48].

Nesterov and Lipatov [49] showed that solid fillers can act as stabilizers for immiscible polymer mixtures. The introduction of a specific filler in binary polymer mixtures was demonstrated to increase the thermodynamic stability of the ternary system. The compatibilizing effect of the filler depends on the change in the free energy of mixing between the two polymers, and the effect is more pronounced for immiscible systems. Specifically, when the fillers localize at the interface between two immiscible polymers, they act as a compatibilizer. Most frequently, the presence of solid fillers at the interface of a blend induces a reduction of the size distribution of the dispersed phase. This concept has been used to control the morphological of polymer blendbased nanocomposites. One of the feasible methods to improve the performance of a polymer blend is by introducing a nanofiller. According to the interaction between the nanofiller (e.g., nanoclay) and the two polymers, three basic structures exist: (1) the nanofiller is dispersed in one phase, (2) the nanofiller is dispersed in both polymer phases and (3) the nanofiller is located at the interface $[50$, 
51]. Concurrently, at least three different morphology changes of polymer blend-based nanocomposites have been observed due to the addition of nanoparticles. In the first type of morphology change, a reduction of the domain size of the dispersed phase is observed, namely, nanoparticles act as a compatibilizer. The second type of morphology change is the alteration from a sea-island to a co-continuous morphology. The third type of morphology change is phase inversion, which is characterized by the transition from a sea-island to a co-continuous and back to a sea-island morphology with the aid of a high shear rate [48].

When nanoparticles are combined with an immiscible polymer blend, they often distribute heterogeneously. The heterogeneous distribution of nanoparticles has been reported to minimize and stabilize the polymer domain size, and in many cases, it broadens the composition range for co-continuity of the polymer blends. This property of nanoparticle/ polymer mixtures attracts great interest because it not only provides a low-cost method for enhancing the function of these nanocomposites but also allows for the modification of their morphologies to optimize their mechanical properties [52]. The addition of nanoparticles to a polymer system with an existing phase-separated morphology, such as a polymer blend, represents an innovative approach to controlling the microstructure and, therefore, the macroscopic properties of the material [53]. Due to the high specific surface area of nanoparticles, the anchoring of the polymer components on the solid nanoparticles is believed to thermodynamically stabilize nano-filled polymer blend systems [54].

Phase continuity development and co-continuous morphologies are highly affected by the nature of the interface in immiscible polymer blends [55]. In general, the mechanical and optical properties of immiscible polymers depend on the disperse phase morphology. During shear flow, the droplet size is a direct result of droplet breakup and coalescence processes [56]. Among the existing polymer morphologies, co-continuous structures are promising because they can combine in unique and synergistic ways the advantages of various polymer components. Polymer materials with co-continuous structures of sub-micrometer size are interesting for many applications such as solar cell panels or separation and catalytic membranes [57]. Additionally, selective filling of conducting fillers in co-continuous, binary, immiscible blends has been exploited for many potential applications such as antistatic devices, electromagnetic interference (EMI) shielding materials, etc. The selective localization of conducting fillers in either of the phases or at the interface of a co-continuous, binary, immiscible polymer blend is a conceptual approach (termed as double percolation) for achieving conducting blends that utilize a very low concentration of conducting fillers [22]. Numerous reports have shown that nanofillers (e.g., nanoclay) can dramatically reduce the size of the dispersed phase in a polymer blend [41]. This change may result from a barrier effect that limits the coalescence of the dispersed phases. The compatibilizing effect and resulting properties are determined by the clay localization and degree of dispersion, which is strongly influenced by the clay-polymer affinity. A marked effect of clay on the refinement of the dispersed phase was found when the clay was present in the matrix phase and at the interface, limiting coalescence due to an active interfacial role of the clay [58]. The observed morphology refinement could be due to the modification of the viscosity ratio between both polymers in the blend [28]. Accordingly, the morphological changes could affect the mechanical properties of the polymer blend nanocomposites.

Adding small amounts of nanoparticles could affect the microstructure of immiscible polymer blends, either causing a drastic size reduction of the minor phase or by promoting the formation of co-continuous morphologies. In other words, nanofiller can be used to promote morphology refinement and $\mathrm{co}$-continuity of a polymer blend. In general the mechanical properties of a polymer blend based nanocomposite can be controlled by the nanofiller induced co-continuous morphology. It is believed that stable co-continuity can form provided that the interfacial tension between the filled and the unfilled polymer phase is balanced by the stress bearing ability of the nanoparticle network [59-62].

In most of the research studies, the degree of the diameter decrease of the dispersed phase was demonstrated to be dependent on the content and type of the polymeric (organic) compatibilizer (e.g., maleic anhydride-grafted compatibilizer). Accordingly, compatibilizers and nanoclays were simultaneously introduced into immiscible polymer blends to achieve a new type of material. Using a maleic anhydride-based compatibilizer and a nanoclay, a high performance PA6 blend that combines the advantages of compat- 
Table 1. Current research on PA6 (rich) blend based-nanocomposites

\begin{tabular}{|c|c|c|c|c|c|}
\hline & $\begin{array}{c}\text { PA6 blend based- } \\
\text { nanocomposites system }\end{array}$ & $\begin{array}{c}\text { Dispersed phase in PA matrix and } \\
\text { its function }\end{array}$ & Nanofiller & Processing technique & Authors \\
\hline 1 & $\begin{array}{l}\text { PA6/PP/MAH- } g-\mathrm{PP} / \\
\text { Organoclay }\end{array}$ & $\begin{array}{l}\text { PP: ensures good processability and } \\
\text { insensitivity to moisture; MAH-g-PP: } \\
\text { compatibilizer }\end{array}$ & $\begin{array}{l}\text { Organoclay } \\
(4 \mathrm{wt} \%)\end{array}$ & Melt compounding & {$[1,12]$} \\
\hline 2 & $\begin{array}{l}\text { PA6/PP/EPR-g-MA/ } \\
\text { Organoclay }\end{array}$ & $\begin{array}{l}\text { PP: ensures good processability and } \\
\text { insensitivity to moisture; EPR-g-MA: } \\
\text { compatibilizer and impact modifier }\end{array}$ & $\begin{array}{l}\text { Organoclay } \\
(4 \mathrm{wt} \%)\end{array}$ & Melt compounding & [13] \\
\hline 3 & $\begin{array}{l}\text { PA6/PP/SEBS-g-MAH/ } \\
\text { Modified MMT }\end{array}$ & $\begin{array}{l}\text { PP: ensures good processability and } \\
\text { insensitivity to moisture; SEBS-g- } \\
\text { MAH: impact modifier }\end{array}$ & $\begin{array}{l}\text { Modified MMT } \\
\qquad(4 \mathrm{wt} \%)\end{array}$ & Melt compounding & {$[16,17]$} \\
\hline 4 & PA6/PP/MAPP/Organoclay & $\begin{array}{l}\text { PP: ensures good processability and } \\
\text { insensitivity to moisture; MAPP: com- } \\
\text { patibilizer }\end{array}$ & $\begin{array}{l}\text { Organoclay } \\
(3.7 \mathrm{phr})\end{array}$ & $\begin{array}{l}\text { Melt compounding (different } \\
\text { mixing protocols) }\end{array}$ & [69] \\
\hline 5 & PA6/HDPE/Organoclay & HDPE: insensitivity to moisture & $\begin{array}{l}\text { Organoclay } \\
(3 w t \%)\end{array}$ & Melt compounding & {$[2]$} \\
\hline 6 & PA6/HDPE/Organoclay & $\begin{array}{l}\text { HDPE: offer high toughness and cost } \\
\text { effective }\end{array}$ & $\begin{array}{l}\text { Organoclay } \\
(5 \mathrm{wt} \%)\end{array}$ & $\begin{array}{l}\text { Melt compounding (different } \\
\text { mixing protocols) }\end{array}$ & [72] \\
\hline 7 & PA6/HDPE/Organo-bentonite & HDPE: insensitivity to moisture & $\begin{array}{l}\text { Organo-ben- } \\
\text { tonite clay } \\
(1.2-2.4 \mathrm{wt} \%)\end{array}$ & Melt compounding & [82] \\
\hline 8 & $\begin{array}{l}\text { Nylon 6/HDPE/ } \\
\text { PE-g-MA/Nanoclay }\end{array}$ & $\begin{array}{l}\text { HDPE: offers low permeability to } \\
\text { water vapor; PE- } g \text {-MA: compatibilizer }\end{array}$ & $\begin{array}{l}\text { Nanoclay } \\
(0.5-3 \mathrm{phr})\end{array}$ & Melt compounding & [83] \\
\hline 9 & $\begin{array}{l}\text { Nylon 6/HDPE/ } \\
\text { PE-g-MA/Modified clay }\end{array}$ & $\begin{array}{l}\text { HDPE: offer high toughness and cost } \\
\text { effective; PE-g-MA: compatibilizer }\end{array}$ & $\begin{array}{l}\text { Modified clay } \\
(0.5-2.5 \mathrm{phr})\end{array}$ & Melt compounding & [99] \\
\hline 10 & PA6/LDPE/Organoclay & $\begin{array}{l}\text { LDPE: offers low permeability to oxy- } \\
\text { gen and water }\end{array}$ & $\begin{array}{l}\text { Organoclay } \\
(0.5-4 \mathrm{phr})\end{array}$ & Melt compounding & [24] \\
\hline 11 & PA6/LDPE/PE-g-MA/Clay & $\begin{array}{l}\text { LDPE: offers low permeability to oxy- } \\
\text { gen and water; PE-g-MA: compatibi- } \\
\text { lizer }\end{array}$ & $\begin{array}{l}\text { Clay } \\
(3 \mathrm{phr})\end{array}$ & Melt compounding & [23] \\
\hline 12 & PA6/PS/Organophilized clays & PS: offers stiffness & $\begin{array}{l}\text { Organophilized } \\
\text { clays }(5 \mathrm{wt} \%)\end{array}$ & Melt compounding & [58] \\
\hline 13 & PA6/PS/Organoclay & PS: offers stiffness & $\begin{array}{l}\text { Organoclay } \\
(2-7 \mathrm{wt} \%)\end{array}$ & $\begin{array}{l}\text { In situ bulk polymerization fol- } \\
\text { lowed by melt compounding }\end{array}$ & [74] \\
\hline 14 & PA6/Polyimide/Organoclay & $\begin{array}{l}\text { Polyimide: offers high-temperature, } \\
\text { high-performance applications }\end{array}$ & $\begin{array}{l}\text { Organoclay } \\
(3 w t \%)\end{array}$ & Melt compounding & [19] \\
\hline 15 & $\begin{array}{l}\text { PA6/Thermotropic liquid } \\
\text { crystalline polymer } \\
\text { (TLCP)/MAPP/Clay }\end{array}$ & $\begin{array}{l}\text { TLCP: possess excellent mechanical } \\
\text { and thermal properties and good anti- } \\
\text { wear properties; MAPP: compatibilizer }\end{array}$ & $\begin{array}{c}\text { Clay } \\
\left(4 w^{2} \%\right)\end{array}$ & Melt compounding & [20] \\
\hline 16 & $\begin{array}{l}\text { PA6/poly(epichlorohydrin-co- } \\
\text { ethylene oxide) } \\
\text { (ECO)/Organoclay }\end{array}$ & $\begin{array}{l}\text { ECO: enhances ductility and impact } \\
\text { strength }\end{array}$ & $\begin{array}{l}\text { Organoclay } \\
(6 w t \%)\end{array}$ & $\begin{array}{l}\text { Two-step melt blending } \\
\text { process }\end{array}$ & {$[3]$} \\
\hline 17 & $\begin{array}{l}\text { PA6/ABS/Styrene-maleic } \\
\text { anhydride copolymer (SMA)/ } \\
\text { Modified montmorillonite }\end{array}$ & $\begin{array}{l}\text { ABS: offers high impact strength } \\
\text { SMA: compatibilizer }\end{array}$ & $\begin{array}{l}\text { Modified mont- } \\
\text { morillonite } \\
(5 \mathrm{wt} \%)\end{array}$ & $\begin{array}{l}\text { Melt compounding (different } \\
\text { mixing protocols) }\end{array}$ & [71] \\
\hline 18 & $\begin{array}{l}\text { PA6/ABS/Ethylene-n butyl } \\
\text { acrylate-carbon monoxide- } \\
\text { maleic anhydride } \\
\text { (EnBACO-MAH)/Nanoclay }\end{array}$ & $\begin{array}{l}\text { ABS: offers high impact strength } \\
\text { EnBACO-MAH: compatibilizer }\end{array}$ & $\begin{array}{l}\text { Nanoclay } \\
(2-4 \mathrm{wt} \%)\end{array}$ & Melt compounding & [85] \\
\hline 19 & $\begin{array}{l}\text { PA6/PP/MPP/Multiwalled } \\
\text { carbon nanotubes (MWNT) }\end{array}$ & $\begin{array}{l}\text { PP: provide a good resistance against } \\
\text { moisture and ensure good processabil- } \\
\text { ity; MPP: compatibilizer }\end{array}$ & $\begin{array}{c}\text { MWNT } \\
(0.4,1,2 \text { phr })\end{array}$ & Melt compounding & [96] \\
\hline 20 & PA6/ABS/MWNT & $\begin{array}{l}\text { ABS: offers high impact strength, } \\
\text { high water resistance and low mold } \\
\text { shrinkage }\end{array}$ & $\begin{array}{l}\text { MWNT } \\
(1-4 \mathrm{wt} \%)\end{array}$ & Melt compounding & {$[22]$} \\
\hline 21 & PA6/ABS/MWNTs & $\begin{array}{l}\text { ABS: offers high impact strength, } \\
\text { high water resistance and low mold } \\
\text { shrinkage }\end{array}$ & $\begin{array}{l}\text { MWNTs } \\
(0.1-1 \mathrm{wt} \%)\end{array}$ & $\begin{array}{l}\text { Master-batch (via solution- } \\
\text { mixing) and melt compound- } \\
\text { ing }\end{array}$ & [4] \\
\hline 22 & $\begin{array}{l}\text { PA6/ABS/Styrene maleic } \\
\text { anhydride copolymer } \\
\text { (SMA)/MWNTs }\end{array}$ & $\begin{array}{l}\text { ABS: offers high impact strength } \\
\text { SMA: reactive compatibilizer }\end{array}$ & $\begin{array}{c}\text { MWNTs } \\
(2 \text { and } 5 \mathrm{wt} \%)\end{array}$ & Melt compounding & {$[100]$} \\
\hline 23 & PA6/PS/MWNTs & PS: offers stiffness & $\begin{array}{c}\text { MWNTs } \\
(0.5-1.5 \mathrm{wt} \%)\end{array}$ & $\begin{array}{l}\text { Successive in-situ polymeriza- } \\
\text { tion }\end{array}$ & [66] \\
\hline 24 & $\begin{array}{l}\text { PA6/PMMA/carboxylic acid } \\
\text { functionalized single walled } \\
\text { carbon nanotubes } \\
\text { (SWCNTs-COOH) }\end{array}$ & $\begin{array}{l}\text { PMMA: improve mixing and miscibil- } \\
\text { ity with PA6 }\end{array}$ & $\begin{array}{l}\text { SWCNTs- } \\
\text { COOH } \\
(1 \mathrm{wt} \%)\end{array}$ & Melt mixing & [26] \\
\hline
\end{tabular}


ibilized polymer blends and the merits of polymer nanocomposites can be prepared. The coalescence of the dispersed minor phase in the PA6 matrix was restricted by the clay, and the interfacial adhesion was improved due to the compatibilizer [63]. In the most ideal model, the clay functions first, decreasing the average diameters of the dispersed particles and stabilizing the morphologies of the blends, and the compatibilizer functions successively, strengthening the interfacial adhesion between the dispersed particles and the matrix.

\subsection{Processing of PA blend-based nanocomposites}

Several processing methods have been employed for the production of thermoplastic nanocomposites such as melt mixing, in situ polymerization, and solution processing. Among these methods, melt mixing of nanofillers with PA blends using conventional processing techniques is particularly desirable because the process is fast, simple, solvent-free and available in the plastic industry. Most of the PA blend-based nanocomposites are prepared by melt compounding, whereas few studies used the combination of in situ polymerization followed by melt mixing. In this review, some processing topics are highlighted, such as the master-batch approach, the effects of mixing conditions and protocols, reactive blending, multiple reprocessing cycles, and the thermal stability (or decomposition) of nanofillers during melt mixing, as well as the innovation in extrusion and molding techniques for PA blendbased nanocomposites.

The master-batch concept has been applied in the processing of PA blend-based nanocomposites. In this way, preformed, largely dispersed master-batches (usually containing $10-20 \mathrm{wt} \%$ nanofiller) are produced. This is an advantageous processing method because hazardous contact with the nano-sized inclusions is reduced to a minimum and the dispersion is close to the optimum [64].

Bose et al. [65] prepared a series of multi-component polymer blends involving PA6, PP, ABS and high-density polyethylene (HDPE) with MWNT [pretreated with either a sodium salt of 6-aminohexanoic acid (Na-AHA) or octadecyl tri-phenyl phosphonium bromide (OTPB)] by melt mixing. The MWNT were either compounded directly or by employing a master-batch dilution approach in binary (PA6/ABS), ternary (PA6/PP/ABS) and quaternary
(PA6/PP/ABS/HDPE) blends. The master batch dilution approach resulted in the selective localization of the pretreated MWNT in the PA6 phase of the multi-component blends, leading to an improvement in the AC electrical conductivity compared with blends prepared by direct addition.

In a study by Liu et al. [4], MWNTs were introduced into PA6/ABS blends without a compatibilizer using melt mixing. To obtain a good dispersion of MWNTs in the blends, a PA6/MWNT master-batch with a relatively high MWNT content was pre-made via solution-mixing with the aid of ultrasonication, and then the master-batch was diluted during the melt mixing. SEM observation showed a good dispersion of MWNTs both in the master-batch and in the blends and revealed that the PA6/ABS (70/30 wt) blends show a sea-island morphology, whereas the PA6/ABS (50/50 wt) blends show a co-continuous morphology. By incorporating MWNTs, the selective distribution of MWNTs in the PA6 phase altered the viscosity ratio of the two phases and led to a stabilization of the interface.

Périé et al. [57] demonstrated that combining master-batch and reactive mixing is a safe and simple method to yield polymer blend nanocomposites. They obtained fine and homogeneous dispersions of carbon nanotubes by mixing master-batches of low molecular-weight amino-terminated PA6 containing 10 or $17 \mathrm{wt} \%$ of MWNT with maleic anhydridefunctionalized polyethylene at temperatures above melting of PA6. The use of PA6-MWNT masterbatches permits the production of conductive nanocomposites with various compositions and a wide range of high performance mechanical properties. Yan and Yang [66] prepared MWNTs-filled PA6/PS blends by in situ successive polymerization. The interface-localized MWNTs can act as a compatibilizer in PA6/PS blends and resulted in both decreased size of the PS domains and increased phase inversion concentration. For the PA6/PS (70/30) blends, the PA6/PS interface was continuous. The interfacelocalized MWNTs could be connected with each other in the continuous interface. Thus, a conductive MWNTs pathway was created, which was effective in decreasing the volume resistivity.

Siengchin and Karger-Kocsis [67] produced ternary composites composed of PA6, hydrogenated nitrile rubber (HNBR) and sodium fluorohectorite $(\mathrm{FH})$ or boehmite alumina (BA) by melt blending with latex pre-compounding. The related master-batch was 
produced by mixing the HNBR latex with water dispersible BA or water swellable FH. The PA6/HNBR/ FH composites produced by the master-batch technique outperformed the PA6/HNBR/BA systems with respect to most of the mechanical and viscoelastic characteristics. This result was attributed to the preferred localization of the $\mathrm{FH}$ in the PA6 matrix and to its higher aspect ratio compared with BA.

One of the factors affecting the structure and properties of polymer blend nanocomposites is the processing route. During melt mixing of the constituents, the particles migrate toward specific regions of the material and are driven by more favorable thermodynamic interactions. However, kinetic effects related to the high viscosity of the polymer melts may lead to non-equilibrium morphologies. This makes the mixing procedure crucial for controlling the space distribution of the nanofiller and, thus, the microstructure of the blend and its final properties [53]. Specifically, the compounding sequence often plays an important role in determining the phase morphology [68]. For melt blending, there are two generally feasible approaches: (1) a one-step process (direct melt blending) in which the polymer and nanofiller are simultaneously loaded and (2) a twostep process that often involves master-batch preparation, e.g., blending the nanofillers with one polymer and adding the second polymer during a second extrusion step.

Filippone and Acierno [53] investigated the effect of the addition sequence of the constituents in blends of PA6 and PS with an organoclay prepared by melt compounding. In the single-step procedure, the filler and the polymers were simultaneously loaded into the mixing apparatus, whereas in the two-step procedure, a homopolymer-based PA6 nanocomposite was first prepared then mixed with the PS. Morphological analyses showed that the filler mainly enriched the more polar PA6 phase, regardless of the mixing procedure. The presence of the filler added via the single-step procedure widened the range of co-continuity and, thus, enhanced the mechanical strength at high temperatures due to the continuity of the PA6 phase.

Wang et al. [69] prepared organoclay-filled PA6/PP/ maleic anhydride-grafted PP (MAPP) blends using four types of compounding sequences (e.g., direct mixing, one-step mixing, a master-batch approach, or a pre-blending approach). The PA6/organoclay master-batch approach resulted in the smallest average domain size because it had the best organoclay dispersion, the highest amounts of PA6 grafted to MAPP, and localization of the organoclay at the interface, which efficiently stabilized the droplets and prevented droplet coalescence. Nevertheless, the use of organoclay in the preparation of $\mathrm{PA} 6 / \mathrm{PP} /$ MAPP blends increased the dynamic storage modulus, regardless of the compounding sequence.

Naderi et al. [70] prepared PA-based nanocomposites in a laboratory mixer using PA6, polyepichlorohydrin-co-ethylene oxide (ECO), and an organoclay by a two-step melt mixing process. First, the PA6 was melt blended with the organoclay and then mixed with ECO rubber. Further intercalation and exfoliation were achieved due to the shear stress developed during the mixing process with ECO, which was due to the increased viscosity. In the PA nanocomposites prepared with 20,30 , and $40 \mathrm{wt} \%$ of ECO, almost complete exfoliation and a random distribution of clay in the thermoplastic phase was observed by X-ray diffraction (XRD) and transmission electron microscopy (TEM) analysis.

Oliveira et al. [71] studied the effects of the mixing protocol on the performance of nanocomposites based on PA6/ABS/OMMT with a styrene-maleic anhydride copolymer (SMA) as a compatibilizer. For all of the blend systems, the OMMT was preferentially located in the PA6 phase and showed an exfoliated structure. The rigidity improvement was greater when the organoclay was located in the phase that had a larger concentration. In contrast, increased toughness in some cases appeared to be greatest when the organoclay was located in the phase that had the minor concentration. In the mixing sequence of (PA6 + OMMT + SMA) + ABS (i.e., a pre-mixture of PA6, OMMT, and SMA was made, and then the PA6/SMA/OMMT nanocomposite was blended with the ABS in a second extrusion), a greater toughness was observed compared with the other sequences, and there were more uniform ABS domains in the PA6 matrix.

Zhang et al. [72] prepared various PA6-HDPE-clay nanocomposites by a two-step extrusion process. The processing sequence played a key role in the clay dispersion and phase morphology of the PA6HDPE-clay nanocomposites. When PA6 was extruded with clay and even in the presence of HDPE in the first extrusion, the resultant PA6-HDPE-clay nanocomposites had a continuous PA6 phase domain 
with exfoliated clay platelets and fine HDPE droplets dispersed in the continuous phase.

According to Dasari et al. [73] it is beneficial in terms of impact strength to have the maximum amount of the exfoliated organoclay in the nylon 66 matrix. Thus blending nylon 66 and organoclay initially and later mixing with SEBS- $g$-MA is the preferred blending sequence to maximize the impact strength. However, if the organoclay is located in the SEBS- $g$-MA phase (as organoclay is blended with SEBS- $g$-MA first) it could reduce the cavitation ability of SEBS- $g$-MA particle, and thus resulting in reduced toughening efficiency.

Although some researchers found that the mixing sequences resulted in significant morphology evolution and resultant changes in the mechanical properties, Wang et al. [35] found that the blending sequence did not exert a large influence on the mechanical properties. They found that a one step blending sequence satisfied their desired balanced mechanical properties for PA6/EPDM- $g$-MA/organoclay ternary nanocomposites.

Compounding procedure represents a versatile parameter for the control of the phase morphology in PA blend-based nanocomposites. In general, different melt blending sequences will give different initial distribution and dispersion states of nanofiller, and subsequently affecting the droplets deformation, breakup and coalescence through viscosity changes and barrier effects of nanofillers. In the presence of compatibilizer it will further influences morphology evolution by reducing interfacial tension and suppressing droplets coalescence. It was found that in most of the cases adding organoclay to the preblend of PA6/the second polymer/maleinized polymer gives the smallest particle size, because the reaction between PA6 and the maleinized polymer can be maximized if organoclay is added after preblending [69].

In general, the microstructure in PA blend-based nanocomposites was significantly influenced by the blending sequence, which affecting their mechanical properties. The changes in mechanical properties (i.e., stiffness, toughness) are largely attributed to the location, dispersion and distribution of the nanofillers in the polymer blends. Thus some of the factors need to be considered for the mixing protocols strategy, for example, priority of select mechanical properties (e.g., stiffness, strength or toughness); materials formulation (e.g., types of PA blends, com- positions [PA-rich or vice versa], nanofiller, compatibilizer, toughener); affinity and preferential location of the nanofiller (e.g., nanoclay selectively located in PA phase rather than non polar polymer phase); rheology behavior (e.g., viscosity changes, shear stress, shear rate) and morphology evolution (e.g., droplets, co-continuous).

Yang et al. [74] synthesized PS/organoclay nanocomposites via in situ bulk polymerization and blended it with PA6 to obtain a ternary nanocomposite. Blending the PS/organoclay nanocomposite previously synthesized via in situ bulk polymerization with PA6 enabled full exfoliation of the organoclay in the final ternary nanocomposite, whereas an intercalated structure was achieved by directly blending the three components. The distribution of the organoclay in the polymer pairs was mainly determined by the surface properties of the clay layers. The increased shear in melt processing is expected to promote the exfoliation of the clay, i.e., the shearing of the clay platelets from the stacks. Ozkoc et al. [75] prepared PA6/ABS/organo-montmorillonite clay using a twin-screw micro-extruder. The operating conditions of the micro-extruder were screw speeds of 100 and $200 \mathrm{rpm}$ and a barrel temperature profile of $235^{\circ} \mathrm{C}$. Doubling the screw speed reduced the dimensions of the dispersed phase and the phases in co-continuous blends. Most of the clays were selectively exfoliated in the PA6 phase.

An additional issue that should be considered is the thermal decomposition of the nanofiller during the melt compounding of PA blend-based nanocomposites. It is well known that the thermal instability of some nanofillers (e.g., ammonium ion-modified clay) is a major limitation for the melt compounding of polymer nanocomposites. The most often used alkyl ammonium surfactants are known to begin degrading at temperatures between 180 and $200^{\circ} \mathrm{C}$, which is within the processing temperature range for most commodity plastics. To obtain nanocomposites without thermal degradation of the organic-modified nanofiller (e.g., organoclay) during processing at higher temperatures (i.e., the PA6 processing temperature of $>230^{\circ} \mathrm{C}$ ), a nanofiller that is thermally stable at temperatures higher than the processing temperatures must be used. Because polymer nanocomposites are also attractive for use in industrial applications, concerns are beginning to be raised about the behavior of such systems. These concerns are related to possible degradation occurring during 
processing and reprocessing, particularly when multiple reprocessing cycles are performed [76]. Scaffaro et al. [77] found that re-extrusion slightly improves the morphology of PA 6/PE blend-clay nanocomposites most likely due to the supplementary stresses induced on the blend in the second processing step, allowing further dispersion of the nanofiller with a consequently higher intercalation level.

\subsection{Properties of PA blend-based nanocomposites}

\subsubsection{Nanoclay-reinforced PA blend-based nanocomposites}

The preparation of polymer/clay nanocomposites has been an important approach to tailor the properties of polymeric materials because of their excellent properties and potential industrial applications. Polymer/layered silicate nanocomposites have attracted recent attention due to the report by the Toyota research group on the improved properties of PA6 nanocomposites, as well as due to the observation by Giannelis and co-workers that their preparation is possible by simple melt mixing of the polymer with the layered silicate [78-80]. In this review, the properties, such as mechanical, thermal, morphological, rheological, water barrier, flame retardancy, and wear resistance, of PA blend-based nanocomposites are highlighted.

In our previous work, we prepared PA6/PP (70/30) nanocomposites using direct melt compounding. The tensile modulus of the PA6/PP increased with increasing OMMT content. The modulus enhancement is attributed to the exfoliation- and reinforcing-ability of OMMT layered silicates. The highest strength values were observed with an organoclay content of $4 \mathrm{wt} \%$ in the blends. The flexural strength was twice the tensile strength, which was attributed to the effect of the injection molding-induced skincore structure and the alignment of the exfoliated/ agglomerated organoclay [12]. Because pristine clay is not compatible with most polymers due to its hydrophilic nature, it must be chemically modified to render its surface more hydrophobic. The most popular surface treatment is ion exchange of the clay with organic ammonium cations, which not only renders its surface more hydrophobic but also expands the spaces between the silicate layers [17, 81]. Modification of clay using various different types of organic modifiers plays an important role for the enhancement of stiffness and strength. Kusmono et al. [17] investigated four different types of OMMT (i.e., dodecylamine-modified MMT (DMMT), 12-aminolauric acid-modified MMT (AMMT), stearylamine-modified MMT (S-MMT), and commercial organo-MMT (C-MMT)) on the properties of PA6/PP blends. The best reinforcement effect was observed for stearylamine modified MMT (S-MMT) due to its longest alkyl chains, largest basal spacing, and better exfoliation in the PA6/PP matrix. Kelnar et al. [58] reported the effect of montmorillonite modification on the behavior of PA/PS blends. The results indicated that nanosilicates can effectively influence the structure of PA/PS blends. The simultaneous reinforcement of both polymer constituents by clay enhanced their stiffness over the entire range of concentrations, whereas strength and toughness were only enhanced for low PS contents. Although the clay was found at the interface in this system, in the case of two rigid polymers (with inclusions even more rigid than the matrix), the core-shell structure did not lead to a toughness enhancement.

In our earlier work, we established that the organoclay is well dispersed (exfoliated) and preferentially embedded in the PA6 phase for a PA6/PP/ organoclay nanocomposite $[12,18]$. Figure 1 shows the TEM images of PA6/PP/OMMT/PP-g-MA nanocomposites. It can be seen that the OMMT silicate layers are exfoliated and selectively located in the PA6 matrix. Fang et al. [82] prepared PA6/HDPE/ organo-bentonite clay and PA6/HDPE-graftedacrylic acid (PEAA)/organo-bentonite clay nanocomposites via melt compounding. The majority of the organoclay platelets were concentrated in the PA6 phase and in the interfacial region between PA6 and HDPE. The organoclay platelets acted as a coupling agent between the two polymers, increasing the interaction of the two phases to a certain extent. These results were confirmed using Fourier Transform Infrared (FTIR) and positron annihilation lifetime spectroscopy. The coarse dispersion of HDPE became markedly finer due to the apparent compatibilization effect of the organoclay. Mallick and Khatua [83] studied the effect of a nanoclay on the morphology of PA6/HDPE (70/30) blends. A reduction in the average domain sizes (D) of the dispersed HDPE phase was observed; therefore, improved mixing was observed compared with the blend without nanoclay. XRD and TEM studies revealed that 


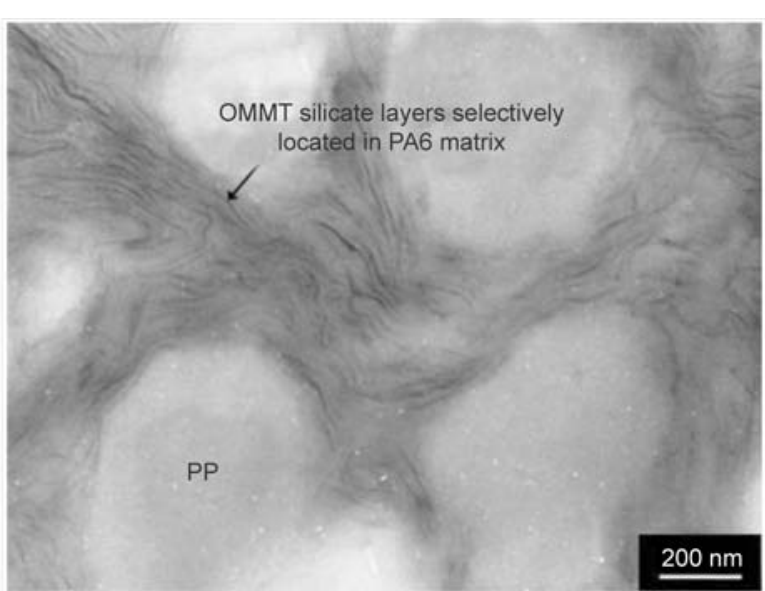

Figure 1. TEM images of PA6/PP/OMMT/PP-g-MA nanocomposites [18]. Reproduced from Kusmono, Mohd Ishak, Chow, Takeichi and Rochmadi by permission of Express Polymer Letters, Budapest University of Technology and Economics, Department of Polymer Engineering, Hungary, Budapest.

the nanoclay layers were mostly located in the PA6 matrix. Taghizadeh et al. [3] reported that the organoclay silicate layers were partially exfoliated in both the PA6 and poly(epichlorohydrin-co-ethylene oxide phases in ternary blends of PA6/ECO/organoclay nanocomposites. A higher level of exfoliation was achieved by increasing the ECO content as a result of the higher shear stress applied to the matrix. Khoshkava et al. [24] found that the LDPE particle size in PA6/LDPE/organoclay nanocomposites was smaller than that in a PA6/LDPE blend. This result could be explained in terms of a reduction in the PE droplet coalescence, enhancement of the interfacial interactions, and improved thermodynamic compatibility between the blend components, all caused by high aspect ratio organoclay platelets.

The rheological behavior of PA6/PP/organoclay (70/30/4) nanocomposites with and without compatibilizers (PP- $g$-MAH and EPR- $g$-MA) was determined by various methods, such as melt flow index (MFI), capillary and plate/plate rheological measurements. Attempts were made to trace the rheological parameters that reliably reflect the observed changes in the clay dispersion. Some parameters in the viscoelastic range were found to be derived from the frequency sweep measurements using a plate/plate rheometer and are suitable indicators for changes in the clay dispersion. Considering the TEM results of the clay dispersions in the nanocomposites, the following rheological parameters in the viscoelastic range at low frequency may be considered as suitable indicators: the storage modulus $\left(G^{\prime}\right)$ and its slope and the complex viscosity $\left(\eta^{*}\right)$ and its slope. The higher $G^{\prime}$ and the smaller the related slope, as well as the higher $\eta^{*}$ and its higher related slope, the better the clay dispersion is [84]. Mojarrad et al. [85] studied the influence of a nanoclay on the rheological properties of PA6/ABS nanocomposites (with ethylene-n butyl acrylate-carbon monoxidemaleic anhydride as a compatibilizer). The incorporation of nanoclay (2-6\%) and ABS (15-35\%) causes increased relaxation times and zero-shear viscosities for all of the blends.

According to Kusmono et al. [86] the initial thermal stability of a PA6/PP blend was improved with the incorporation of both Na-MMT and OMMT. Dynamic Mechanical Analysis (DMA) and heat distortion temperature (HDT) results confirmed the higher values in both the storage modulus and the HDT in the PA6/PP/4Na-MMT and PA6/PP/ 4OMMT nanocomposites. This result may be attributed to the presence of strong hydrogen bonds between the polymer matrix and clay surface. Varley et al. [19] prepared PA6/low-molecular-weight polyetherimide/organoclay using a twin-screw extruder. The addition of small quantities of a commercial polyimide substantially improved the HDT and the glass transition temperatures of PA6/clay nanocomposites.

The water absorption and hygrothermal aging behavior of PA6/PP/organoclay/MAH-g-PP nanocomposites was studied at three different temperatures (30, 60 , and $90^{\circ} \mathrm{C}$ ). The equilibrium moisture content and the diffusion coefficient were dependent on the OMMT loading, MAH-g-PP concentration, and immersion temperatures. At any immersion temperature, the MAH-g-PP-compatibilized PA6/PP/ OMMT nanocomposites showed excellent retention ability and recovery properties. The presence of MAH- $g$ PP not only enhanced the resistance of the nanocomposites against direct water immersion but also improved the resistance of the composites against hygrothermal attack [87].

Lu et al. [27] utilized ammonium polyphosphate (APP) and clay to improve the flame resistance of PA6/PS blends. In the blends with a continuous PA6 phase and a dispersion of clay at interface, the aggregation of clay platelets at the interface benefited the formation of a compact residue char on outer surface and a loose and large porosity on inner surface. 
This morphology was more effective at delaying thermal degradation, resulting in improved of thermal stability.

Dayma et al. [88] reported that the incorporation of nanoclay into a PA6/PP-g-MA binary blend matrix caused an enhancement in the wear resistance. The wear surface morphology studies indicated a transition in the wear failure mechanism from matrixdominated plastic-flow to shear-induced low-intensity ductile-chipping with the increase in nanoclay content, which plays a determining role in controlling the sliding wear performance.

\subsubsection{CNT-reinforced PA blend-based nanocomposites}

Carbon nanotube (CNT)-modified polymer blends have attracted a large amount of attention in recent years. Most researchers reported that CNT-filled immiscible polymer blends with co-continuous morphologies usually exhibit excellent electrical conductivity due to the selective distribution of the CNTs in one phase even if the CNT content is very low. In addition, altering the morphology of immiscible polymer blends is possible by adding CNTs $[48,89]$. CNTs have emerged as potential conducting fillers due to their exceptional electrical properties and high aspect ratio $(L / D)$. Thus, a very high conductivity in the polymer/CNT nanocomposites can be achieved with very low CNT concentrations [90]. However, due to strong inter-tube van der Waals forces and the lack of interfacial interactions with the polymer matrix, CNTs tend to agglomerate to form clusters (or insufficient de-agglomeration) and often manifest a higher electrical percolation threshold with a lower effective $L / D$. Hence, an effective $L / D$ is a key factor in achieving a low electrical percolation threshold in the polymer matrix. In addition, adequate interfacial interaction between the CNTs and the polymer matrix is another prerequisite for obtaining enhanced dispersions of CNTs. To this end, functionalization of CNTs is one of the strategies employed to enhance their phase adhesion with the polymer matrix [22]. Most of the research regarding CNT-reinforced PA blend-based nanocomposites is focused on the morphological evolution and electrical properties.

Bose et al. [22] prepared co-continuous blends of PA6 and ABS containing multiwall carbon nanotubes (MWNT) using a conical twin-screw microcompounder. The electrical and rheological percola- tion thresholds in PA6/ABS blends were 3-4 and 1$2 \mathrm{wt} \%$ MWNT, respectively. A unique reactive modifier (sodium salt of 6-amino hexanoic acid, Na-AHA) was employed to facilitate the networklike structure of the MWNT and to confine them in a specific phase. This morphology was achieved by establishing specific interactions with the delocalized ' $\pi$-electron' clouds of the MWNT and the meltinterfacial reaction during melt mixing. A significant refinement in the co-continuous structure was observed in the blends in presence of Na-AHAmodified MWNT. TEM investigations revealed a uniform dispersion and the selective localization of the MWNT in the PA6 phase of the blends in the presence of Na-AHA. A similar observation was reported by Zhang et al. [91] for PA6/PP/MWNTs nanocomposites and Liu et al. [4] for PA6/ABS/ MWNTs nanocomposites.

According to Zhang et al. [91], the MWNTs preferentially located in the PA6 phase, and a small amount of the MWNTs bridged the PA6 and PP phases. Liu et al. [4] observed a homogeneous and selective dispersion of MWNTs in the PA6 phase, a significant morphology refinement with reduced sizes of the ABS domains, and a stabilized interface.

Xiang et al. [48] investigated the effect of functionalized multiwall carbon nanotubes (FMWCNTs) on the phase morphology of immiscible PA6/HDPE blends. Adding small amounts of FMWCNTs $(<2.0 \mathrm{wt} \%)$ did not exert a profound influence on the sea-island morphology of the nanocomposites. However, a typical co-continuous morphology was detected with moderate content of FMWCNTs (2.0 and $5.0 \mathrm{wt} \%$ ). Further increasing the FMWCNT content $(10.0 \mathrm{wt} \%)$ induced phase inversion.

Madhukar et al. [26] demonstrated that uniform PMMA dispersion is achieved by the addition of carboxylic acid-functionalized single walled carbon nanotubes (SWCNTs-COOH) in PA6/PMMA. The SWCNTs-COOH acted as a compatibilizer of PA6/ PMMA by inducing hydrogen bonding between PA6 and PMMA.

\subsubsection{Effects of polymeric compatibilizer on the PA blend-based nanocomposites}

Blending commercial polymers to produce new materials with targeted properties is a popular and attractive topic. The final aim is to promote synergism among the immiscible polymer pairs to form blends with enhanced or new, tailored properties 
with respect to the parent components. Normally, a compatibilization step is needed to improve the otherwise weak interfacial adhesion and to reduce the morphological instability of the straight blends [81]. A compatibilizer is usually added into immiscible polymer blends to intensify the interfacial strength because it has similar chain structures to the two components of the polymer blend or it reacts with one component via the functional groups (sometimes forming hydrogen bonds). Furthermore, the addition of a compatibilizer also reduces the diameters of the dispersed minor polymer phase by reducing the interfacial tension within the blend [63].

The achievement of compatibilization, whether by the addition of a third component (i.e., a compatibilizer) or by an in situ chemical reaction between the blend components (reactive blending), has played an important role in the development of polymer blends. Physical and reactive compatibilizations are used to reduce the interfacial tension between the two phases and to improve their interfacial adhesion. Block and graft copolymers with covalently connected immiscible blocks have demonstrated effective compatibilization in immiscible blends [92].

In our previous work, we have shown the peculiar clay dispersion in PA6/PP blends with and without compatibilizer. The major results of this work were that the exfoliated/intercalated clay layers were exclusively located in the more polar PA6 phase in the uncompatibilized blends and that adding a maleated compatibilizer results in a finer dispersion of the organoclay (octadecylamine-intercalated montmorillonite). Furthermore, the clay layers were preferentially embedded in a PA6-grafted polyolefin phase, formed via chemical reactions between the primary and secondary amines of the PA6 and the anhydride groups of the maleated polypropylene (MAH-g-PP) and ethylene/propylene rubber (EPR- $g$-MA), respectively. The melt viscosity of the compatibilizer (EPR$g$-MA $>$ MAH-g-PP) was suggested to also affect the dispersion state of the organoclay [84].

The strength and stiffness of the PA6/PP nanocomposites were significantly improved in the presence of MAH- $g$-PP. This result was attributed to the synergistic effect of the organoclay and MAH-g-PP. The MAH-g-PP-compatibilized PA6/PP nanocomposites showed a homogeneous morphology, supporting the compatibility improvement between PA6, PP and the organoclay [1]. Adding EPR-g-MA to the PA6/PP (70/30) blends resulted in a finer dis-

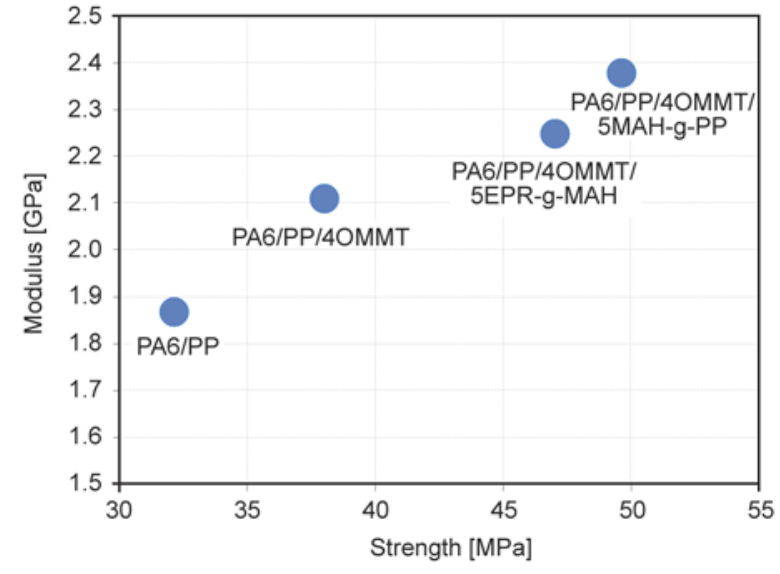

Figure 2. Effects of compatibilizer (MAH-g-PP and EPR$g$-MA) and OMMT on the modulus and strength improvement of the PA6/PP blends

persion of the PP phase. The storage $\left(G^{\prime}\right)$ and loss moduli $\left(G^{\prime \prime}\right)$ assessed using plate/plate rheometry of the PA6/PP blends increased with the incorporation of EPR-g-MA and organoclay. Furthermore, the apparent shear viscosity of the PA6/PP blend significantly increased for the EPR-g-MA-compatibilized PA6/PP/organoclay nanocomposite. This result was traced to the formation of an interphase between PA6 and PP (via PA6- $g$-EPR) and effective intercalation/ exfoliation of the organoclay [13]. Figure 2 shows the effects of compatibilizer (MAH- $g$-PP and EPR$g$-MA) and OMMT on the modulus and strength improvement of the PA6/PP. It can be seen that the modulus/strength of PA6/PP/4OMMT/5MAH- $g$-PP $>$ PA6/PP/4OMMT/5EPR-g-MAH $>$ PA6/PP/4OMMT $>$ PA6/PP.

The phase structure and clay dispersion in $\mathrm{PA} 6 / \mathrm{PP} /$ organoclay (70/30/4) systems with and without an additional 5 parts of maleated polypropylene (MAH$g$-PP) as a compatibilizer were studied using atomic force microscopy (AFM). AFM scans were taken from the polished surface of specimens that were chemically and physically etched with formic acid and argon ion bombardment (technique adopted from Karger-Kocsis et al. [93]), respectively. The latter technique was found to be very sensitive to the blend morphology; PP was far more resistant to ion bombardment than PA6. The organoclay was located in the PA6 phase in the uncompatibilized blends, whereas it was embedded in the PA6-g-PP phase in the PA6/PP blends compatibilized with MAH-g-PP. This information was deduced from the AFM scans performed on physically etched samples. The preferential location of the clay in the PA6-g- 
PP phase was traced to possible chemical interactions between the PA6 and the organic intercalant of the clay [94].

According to Kusmono et al. [18], the presence of PP- $g$-MA in the PA6/PP/dodecylamine-modified MMT (OMMT) nanocomposite enhanced the properties such as stiffness, strength, ductility, impact strength, and HDT. This result was attributed to the compatibilizing effect of PP-g-MA, which improved the interfacial adhesion between the OMMT and the PA6/PP matrix and also promoted the exfoliation of silicate layers in the PA6/PP matrix [18]. The OMMT selectively localized in the PA6 matrix. A similar observation was also reported by Covas et al. [95] on the PA/PP/alkyl ammonium-modified montmorillonite nanoclay.

Ozkoc et al. [75] reported that addition of carbon monoxide-modified ethylene-n-butyl acrylate-maleic anhydride (EnBACO-MAH) as a compatibilizer resulted in a decrease in the dispersed phase morphology for a compatibilized PA6/acrylonitrile-butadiene-styrene (ABS)/organoclay system. TEM micrographs showed that the clays were selectively dispersed in the PA6 phase.

Zhang et al. [96] used maleated polypropylene (MPP) as a compatibilizer for multiwall carbon nanotube (MWNTs)-reinforced PA6/PP (70/30) composites. The MPP and MWNTs had a synergistic effect on the improvement of the thermal stability. Adding MPP (5 phr) significantly increased the tensile, flexural and impact strength of PA6/PP/MWNTs nanocomposites (70/30/0.4) approximately 5.3, 8.6 and $70.4 \%$, respectively.

Zhang et al. [20] prepared two hybrid nanocomposites by melt blending a thermotropic liquid crystalline polymer (TLCP) and a well-dispersed PA6/ clay nanocomposite (with and without the incorporation of maleic anhydride grafted polypropylene (MAPP) as a compatibilizer). The addition of MAPP improved the compatibility between TLCP and the matrix and thus enhanced the fibrillation of the dispersed TLCP phase. The wear resistance of the MAPP-compatibilized hybrid nanocomposite was effectively improved, as indicated by the low values of the specific wear rate and the frictional coefficient, especially under high-normal load (i.e., $80 \mathrm{~N}$ ). For the compatibilized PA6/TLCP/OMMT/ MAPP nanocomposite, the debris formed a compact and uniform transfer film on the counter surface.
Malmir et al. [23] studied the rheology and morphology of PA/PE/clay hybrid nanocomposites. The rheological measurements indicated that the loading of clay into a PA/PE blend dramatically increased its viscosity and elasticity compared with that of pure PE and PA, especially in the presence of a maleic anhydride-grafted polyethylene (PE-g-MA) compatibilizer. The PA/PE nanocomposite with PE$g$-MA compatibilizer exhibited higher melt viscosity and storage modulus than the nanocomposite without compatibilizer, which was related to improved dispersion and polymer-silicate interactions.

In recent years, new compatibilization strategies have been explored, such as using inorganic nanofillers. Finer dispersion of the minor phase and a more stable phase morphology of the polymer blends were achieved by incorporating nanofillers [97]. The most crucial factor in the enhancement of properties in nanocomposites is the extent of interaction between the nanofiller and the polymer matrix, which leads to the selective localization of the nanofiller in multiphase systems. In this context, the addition of a compatibilizer to a nanofiller-containing multiphase system can contribute towards nanofiller positioning and its state of dispersion due to the induced changes in the thermodynamic system [98].

Mallick et al. [99] reported the synergistic effect of nanoclay and maleic anhydride-grafted polyethylene (PE- $g$-MA) on the morphology and properties of nylon 6/high density polyethylene (HDPE) blends. The size of phase separated domains decreased considerably with increasing nanoclay content and PE$g$-MA. The addition of PE- $g$-MA in the blend-clay nanocomposites enhanced the exfoliation of the clays in the PA6 matrix, especially at the interface. Simultaneously, PE-g-MA improved the adhesion between the phases at the interface.

Jogi et al. [100] investigated the effect of simultaneous addition of multiwall carbon nanotubes (MWNTs) and a reactive compatibilizer (styrene maleic anhydride copolymer, SMA) during melt mixing on the phase morphology of a PA6/ABS $(80 / 20)$ blend. Fourier transform infrared spectroscopic (FTIR) analysis indicated the formation of imide bonds during melt mixing. The SMA copolymer acted as a reactive compatibilizer, reduced the interfacial tension and lowered the rate of coalescence; therefore, it stabilized the phase morphology of the blends and led to higher storage modulus. 
Table 2. Mechanical properties of compatibilized PA6-blend based nanocomposites

\begin{tabular}{|c|c|c|c|c|c|c|c|}
\hline & $\begin{array}{c}\text { PA6-blend based } \\
\text { nanocomposites system }\end{array}$ & $\begin{array}{c}\text { Nanofiller types and } \\
\text { loading }\end{array}$ & $\begin{array}{l}\text { Compatibilizer types } \\
\text { and loading }\end{array}$ & $\begin{array}{c}\text { Tensile } \\
\text { strength } \\
\text { [MPa] }\end{array}$ & $\begin{array}{c}\text { Tensile } \\
\text { modulus } \\
\text { [GPa] }\end{array}$ & $\begin{array}{c}\text { EB } \\
{[\%]}\end{array}$ & Ref. \\
\hline \multirow{3}{*}{1} & $\begin{array}{l}\text { PA6/PP } \\
(70 / 30)-\text { control }\end{array}$ & - & - & 32.1 & 1.87 & 22.8 & \multirow{3}{*}{ [1] } \\
\hline & $\begin{array}{l}\text { PA6/PP/organoclay } \\
(70 / 30 / 4)\end{array}$ & $\begin{array}{l}\text { Organoclay intercalated } \\
\text { by octadecylamine } / 4 \mathrm{phr}\end{array}$ & - & $\begin{array}{c}38.0 \\
{[+17.4 \%]}\end{array}$ & $\begin{array}{c}2.11 \\
{[+12.8 \%]}\end{array}$ & $\begin{array}{c}4.2 \\
{[-81.5 \%]}\end{array}$ & \\
\hline & $\begin{array}{l}\text { PA6/PP/MAH- } g \text {-PP/organoclay } \\
(70 / 30 / 5 / 4)\end{array}$ & $\begin{array}{l}\text { Organoclay intercalated } \\
\text { by octadecylamine } / 4 \mathrm{phr}\end{array}$ & $\begin{array}{l}\text { MAH- } g \text {-PP with } 1.2 \mathrm{wt} \% \\
\text { of maleic anhydride } \\
\text { (MA) } / 5 \mathrm{phr}\end{array}$ & $\begin{array}{c}49.6 \\
{[+54.5 \%]}\end{array}$ & $\begin{array}{c}2.38 \\
{[+27.3 \%]}\end{array}$ & $\begin{array}{c}4.8 \\
{[-78.9 \%]}\end{array}$ & \\
\hline \multirow{3}{*}{2} & $\begin{array}{l}\text { PA6/PP } \\
(70 / 30)-\text { control }\end{array}$ & - & - & 32.1 & 1.87 & 22.8 & \multirow{3}{*}{ [13] } \\
\hline & $\begin{array}{l}\text { PA6/PP/organoclay } \\
(70 / 30 / 4)\end{array}$ & $\begin{array}{l}\text { Organoclay intercalated } \\
\text { by octadecylamine } / 4 \mathrm{phr}\end{array}$ & - & $\begin{array}{c}38.0 \\
{[+17.4 \%]}\end{array}$ & $\begin{array}{c}2.11 \\
{[+12.8 \%]}\end{array}$ & $\begin{array}{c}4.2 \\
{[-81.5 \%]}\end{array}$ & \\
\hline & $\begin{array}{l}\text { PA6/PP/EPR-g-MA/organoclay } \\
(70 / 30 / 5 / 4)\end{array}$ & $\begin{array}{l}\text { Organoclay intercalated } \\
\text { by octadecylamine } / 4 \mathrm{phr}\end{array}$ & $\begin{array}{l}\text { EPR- } g \text {-MA containing } \\
1 \mathrm{wt} \% \mathrm{MA} / 5 \mathrm{phr}\end{array}$ & $\begin{array}{c}47.0 \\
{[+46.4 \%]}\end{array}$ & $\begin{array}{c}2.25 \\
{[+20.3 \%]}\end{array}$ & $\begin{array}{c}6.7 \\
{[-70.6 \%]}\end{array}$ & \\
\hline \multirow{3}{*}{3} & $\begin{array}{l}\text { PA6/PP } \\
(70 / 30)-\text { control }\end{array}$ & - & - & 44.0 & - & - & \multirow{3}{*}{ [96] } \\
\hline & \begin{tabular}{|l|} 
PA6/PP/MWNT \\
$(70 / 30 / 0.4)$
\end{tabular} & $\begin{array}{l}\text { Multiwalled carbon nan- } \\
\text { otube } / 0.4 \mathrm{phr}\end{array}$ & 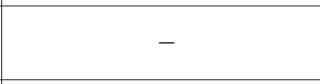 & $\begin{array}{c}57.1 \\
{[+29.8 \%]}\end{array}$ & - & - & \\
\hline & $\begin{array}{l}\text { PA6/PP/MPP/MWNT } \\
(70 / 30 / 5 / 0.4)\end{array}$ & $\begin{array}{l}\text { Multiwalled carbon nan- } \\
\text { otube } / 0.4 \mathrm{phr}\end{array}$ & $\begin{array}{l}\text { Maleated polypropylene } \\
\text { (MPP) } / 5 \mathrm{phr}\end{array}$ & $\begin{array}{c}60.1 \\
{[+36.6 \%]}\end{array}$ & - & - & \\
\hline \multirow{3}{*}{4} & $\begin{array}{l}\text { PA6/HDPE } \\
(80 / 20)-\text { control }\end{array}$ & - & - & 24.5 & 2.26 & 13.4 & \multirow{3}{*}{ [99] } \\
\hline & $\begin{array}{l}\text { PA6/HDPE/Nanoclay } \\
(80 / 20 / 0.5)\end{array}$ & Nanoclay $/ 0.5 \mathrm{phr}$ & - & $\begin{array}{c}29.6 \\
{[+20.8 \%]}\end{array}$ & $\begin{array}{c}2.82 \\
{[+24.8 \%]}\end{array}$ & $\begin{array}{c}11.8 \\
{[-11.9 \%]}\end{array}$ & \\
\hline & $\begin{array}{l}\text { PA6/HDPE/PE- } g \text {-MA/Nanoclay } \\
(80 / 20 / 0.5 / 0.5)\end{array}$ & Nanoclay $/ 0.5 \mathrm{phr}$ & PE-g-MA/0.5 phr & $\begin{array}{c}32.8 \\
{[+33.9 \%]}\end{array}$ & $\begin{array}{c}2.98 \\
{[+31.8 \%]}\end{array}$ & $\begin{array}{c}13.6 \\
{[+1.49 \%]}\end{array}$ & \\
\hline
\end{tabular}

Note: Value in [ ] indicates the percentage of properties changes compare to control sample (i.e., PA6 blends).

Table 2 shows the mechanical property changes of compatibilized PA6-blend based nanocomposites. The mechanical properties (modulus, strength, and elongation at break) are highly governed by the nanofillers and compatibilizers. In general, the effectiveness of compatibilization is dependent on several factors: (1) the nature and types of PA6 blends (e.g., their continuous and dispersed phases, co-continuous morphology), (2) the type and loading of nanofillers (e.g., surface modified or unmodified), and (3) the type and loading of the compatibilizer (e.g., grafting percentage of MA, content of reactive groups).

\subsubsection{Toughening strategies for PA blend-based nanocomposites}

To improve the toughness of PA nanocomposites, many investigations regarding blends with styreneethylene/butylene-styrene triblock copolymer (SEBS), ethylene-propylene random copolymer (EPR), ethylene/1-octene copolymer (EOR), ethylene-polypropylene-diene copolymer (EPDM), and metallocene EPDM/maleated EPDM copolymer (mEPDM/EPDM-g-MA) have been reported. Toughness is usually achieved at the expense of strength and stiffness. Many investigations have been directed towards improving the toughness-to-stiffness balance in PA. The stiffness of rubber-toughened PA can be restored by the addition of inorganic fillers [34]. In contrast, the toughness of PA nanocomposites can be improved by the addition of a suitable impact modifier. In this review, we mainly emphasize the toughness improvement of PA blend (thermoplastic-thermoplastic)-based nanocomposites (for example, PA6/PP/nanofiller, PA6/HDPE/nanofiller, and PA6/PS/nanofiller).

The addition of a nanofiller into a PA6 blend system, for example, in the case of PA6/PP/organoclay nanocomposites, drastically decreased the impact strength. The reduction in impact strength could be attributed to the immobilization of the macromolecular chains by the clay particles, which limited their ability to adapt to deformation and resulted in a more brittle material. In addition, each silicate layer (especially aggregates of silicate layers) was the site of stress concentration and could act as a micro crack initiator.

Among the already studied toughened PA6/PP nanocomposites, we can include PA6/PP/organoclay/ maleated ethylene-propylene rubber (EPR-g-MA) 
[13], PA6/PP/organoclay/polyethylene octane elastomer (POE) [14], PA6/PP/clay/maleic anhydride polyethylene octane elastomer (POE-g-MA) [15], and PA6/PP/modified clay/maleated styrene-ethylene-butylene-styrene (SEBS-g-MA) [16, 17]. Chow et al. [13] and Wahit et al. [14] demonstrated that the ductility and toughness of PA6/PP/organoclay nanocomposites improved by the addition of EPR$g$-MA and POE, respectively.

According to Kusmono et al. [16] the incorporation of maleated styrene-ethylene-butylene-styrene (SEBS-g-MA) increased the fracture toughness (assessed by single edge notched three point bending tests) of PA6/PP/organoclay (70/30/4) nanocomposites. The increase in ductility and fracture toughness at high testing speeds could be attributed to the thermal blunting mechanism in front of the crack tip [16]. The rubber particles dispersed within a neat PA6 matrix increased the toughness via cavitation, which relieves the triaxial stress state ahead of the advancing crack trip and allows the PA6 matrix to shear yield, thereby dissipating more energy and enhancing the toughness [17]. A similar finding was reported by Attari et al. [101] for PA6/HDPE/SEBS$g$-MA/modified clay nanocomposites. The presence of SEBS- $g$-MA improved the toughness and thermal properties of PA6/HDPE/modified clay nanocomposites. In another work by Kusmono et al. [102], a SEBS-g-MA compatibilizer was more efficient in improving the fracture toughness of PA6/ $\mathrm{PP} / \mathrm{OMMT}$ nanocomposites than a PP-g-MA compatibilizer at high testing speeds (i.e., tensile testing speed of $500 \mathrm{~mm} / \mathrm{min}$ ).

Chen et al. [21] prepared PA66/PA6/organoclay ternary nanocomposites by mixing PA6 and OMMT as a master-batch and then blending it with PA66 and different elastomers in a twin-screw extruder. The incorporation of POE- $g$-MA markedly toughened the nanocomposites. A PA66-co-POE-g-MA copolymer formed in situ during the melt extrusion of PA66 and POE-g-MA improved the compatibility between PA66 and POE- $g$-MA by lowering the interfacial tension and thus decreasing the sizes of the POE- $g$ MA particles. The smaller POE-g-MAH domains are hypothesized to toughen the blends.

The application of elastomeric tougheners in nanocomposites usually leads to an increase in toughness at the expense of stiffness and strength. In contrast, when applying the compatibilization reinforcement concept to an elastomer-toughened PA6 nanocomposite, Kelnar et al. [103] found a significant size reduction and modification of the dispersed phase morphology. TEM showed the formation of core-shell particles (rubber surrounded by stacks of clay platelets) enhancing the toughening effect of the elastomer. As a result, the simultaneous enhancement of the strength, toughness and stiffness was achieved. Additionally, taking into account the potential of clay-compatibilization, which leads to a dispersed core/shell rubber phase with enhanced toughening ability, Kelnar et al. [104] studied the PA6/PS/ethylene propylene elastomer (EPR)/nanoclay system (i.e., nanocomposite with ternary matrix consisting of PA6 with dispersed rubbery and rigid polymer phases). The addition of nanoclay to the PA6/PS/EPR matrix led to a decrease in the particle size. However, the presence of the nanoclay in a ternary matrix caused predominantly opposite changes in mechanical behavior compared with binary blends. The differences include a decrease in toughness with increasing clay content and a less effective toughening effect of the core-shell (elastomer/ clay) particles. Thus, a proper combination of rigid and elastomeric inclusions should be selected to achieve nanocomposites with balanced mechanical behavior.

\section{Future challenges and conclusion remarks}

As illustrated within this review, nanofillers represent an interesting method to extend and to improve the properties of PA blends to prepare high-performance PA blend-based nanocomposites. The properties of PA blend-based nanocomposites are influenced by various factors such as the compositions, morphologies, interfacial interactions, nanofillers and processing methods (see Figure 3 ). The superior properties derived through the combination of PA blends and nanofiller appear to be relevant in the development of materials for various applications. However, there are some challenges of particular note. These include:

(1). Nanofillers tend to agglomerate, which can influence the dispersibility and interfacial interaction with the polymer; thus, the incorporation of nanofiller in a PA blend matrix must overcome processing and dispersion challenges. A new route of PA blend based nanocomposites processing, for example, water injectionassisted melt compounding (see contribution works from Siengchin and Karger-Kocsis 


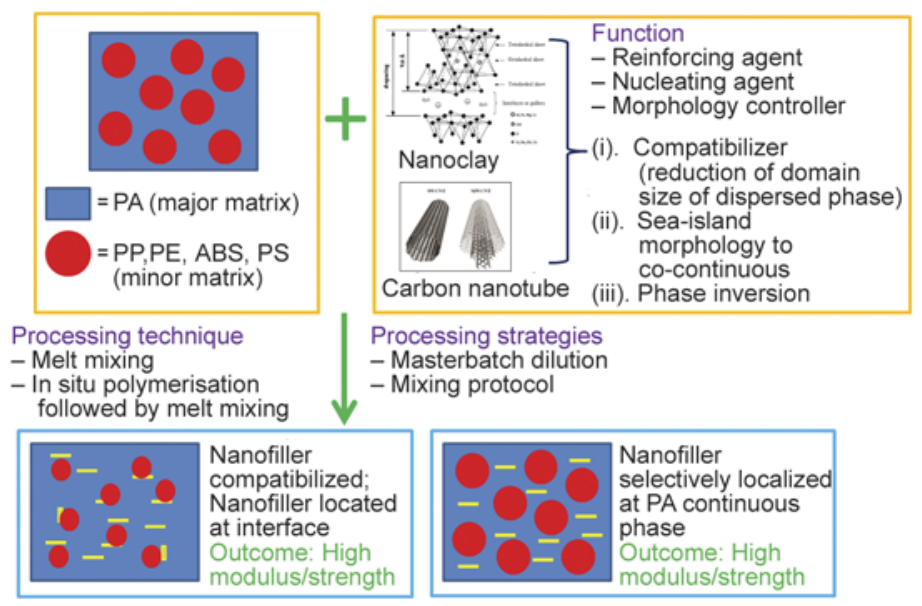

Figure 3. Structure-properties-processing relationship of PA blend-based nanocomposites

[105]) and ultrasound assisted melt compounding is potential and feasible.

(2). The surface chemistry of the nanofiller has a dramatic influence on their localization in the PA blend and hence on the possible compatibilizing role and on the final properties. In most cases, the localization of nanofiller at the interface is not often accurate and the size and surface chemistry are not well-controlled parameters; thus, nanofillers with desired surface properties with controllable localization and dispersion in PA blends should be further developed. This is of great importance for nanoparticleinduced morphology control.

(3). The interfacial strength of PA blends and nanofiller is always a challenge in the development of a high performance nanocomposites; thus, suitable surface modification of nanofiller and compatibilization technique must be selected in order to maximize the properties of PA blendbased nanocomposites. In this aspect, the research work carried out by Karger-Kocsis's group is worth mention. With the presence of a selected compatibilizer and appropriate mixing protocol, well-functionalized nanoparticles can be located at the interface and thus stabilize the morphology of a polymer blend. Thus, the compatibilization mechanisms contribute to a finer morphology of polymer-blend based nanocomposites. In addition, the interaction of compatibilizer (e.g., maleic-anhydride based) and nanofiller is essential to control the preferential state of the nanofillers in the selected polymer phase $[68,97]$.

(4). Nanofillers such as halloysite nanotubes (HNTs) make it possible, in contrast to other nano- fillers, to significantly reduce the ductility loss upon addition in a polymer matrix (e.g., PP, PA6 and linear low density polyethylene (LLDPE) - as reported in ref [106-108]). We believe that adding HNT into PA6 blends could be a feasible approach to prepare nanocomposites with a good balance in strength, stiffness and toughness because HNT works well with both PA and polyolefin (e.g., PP, LLDPE). In addition, graphene, a new generation carbonaceous-layered material has shown considerable potential as a reinforcing material in polymer nanocomposites. It has a very large surface area and tunable surface properties [109-114]. Graphene is a good candidate that can be used to improve the mechanical (e.g., modulus, strength, creep resistance) and electrical properties of PA blend-based nanocomposites and hence widen the multi-functionality needed for electronic applications (e.g., electrical energy storages, actuations, flexible electronics, electromagnetic interference shielding and sensors) and corrosion resistance and gas barrier properties.

\section{List of abbreviation}

ABS:

ABS- $g-\mathrm{MA}:$

acrylonitrile-butadiene-styrene

A-MMT: $\quad 12$-aminolauric acid modified montmoacrylonitrile-butadiene-styrene coreshell rubber rillonite

APP: $\quad$ ammonium polyphosphate

AFM: $\quad$ atomic force microscopy

BA: boehmite alumina

C-MMT: commercial organo-montmorillonite

CNT: $\quad$ carbon nanotube

D-MMT: dodecylamine modified montmorillonite 


\begin{tabular}{|c|c|}
\hline DPIM: & dynamic packing injection molding \\
\hline ECO: & polyepichlorohydrin-co-ethylene oxide \\
\hline EMI: & electromagnetic interference \\
\hline EnBACOMAH: & $\begin{array}{l}\text { carbon monoxide-modified ethylene-n- } \\
\text { butyl acrylate-maleic anhydride }\end{array}$ \\
\hline EOR: & ethylene-1-octene \\
\hline EPDM: & $\begin{array}{l}\text { ethylene-propylene-diene metallocene } \\
\text { terpolymer }\end{array}$ \\
\hline EPDM- $g$-MA : & $\begin{array}{l}\text { maleated ethylene-polypropylene-diene } \\
\text { copolymer }\end{array}$ \\
\hline EPR: & ethylene-propylene random copolymer \\
\hline EPR-g-MA: & maleated ethylene/propylene rubber \\
\hline FH: & sodium fluorohectorite \\
\hline FMWCNT: & $\begin{array}{l}\text { functionalized multiwall carbon nan- } \\
\text { otubes }\end{array}$ \\
\hline FTIR: & fourier transform infrared spectroscopic \\
\hline HDPE: & high density polyethylene \\
\hline HDT: & heat distortion temperature \\
\hline HNBR: & hydrogenated nitrile rubber \\
\hline HNT: & halloysite nanotubes \\
\hline LDPE: & low density polyethylene \\
\hline LLDPE: & linear low density polyethylene \\
\hline MA: & maleic anhydride \\
\hline MAH-g-PP: & maleated polypropylene \\
\hline MAPP: & maleic anhydride grafted PP \\
\hline MAV: & $\begin{array}{l}\text { maleic anhydride intercalated vermicu- } \\
\text { lite }\end{array}$ \\
\hline mEPDM: & $\begin{array}{l}\text { metallocene ethylene-polypropylene- } \\
\text { diene copolymer }\end{array}$ \\
\hline mEPR: & maleinized ethylene-propylene-rubber \\
\hline MFI: & melt flow index \\
\hline MMT: & montmorillonite \\
\hline MPP: & maleated polypropylene \\
\hline mSEBS: & $\begin{array}{l}\text { maleinized styrene-ethylene-butylene- } \\
\text { styrene }\end{array}$ \\
\hline MWNT: & multi-walled carbon nanotube \\
\hline Na-AHA: & sodium salt of 6-aminohexanoic acid \\
\hline Na-MMT: & sodium montmorillonite \\
\hline NBR: & acrylonitrile butadiene rubber \\
\hline OMMT: & organo-montmorillonite \\
\hline OTPB: & $\begin{array}{l}\text { octadecyl tri-phenyl phosponium bro- } \\
\text { mide }\end{array}$ \\
\hline PA: & polyamide \\
\hline PA6: & polyamide 6 \\
\hline PA66: & polyamide 66 \\
\hline PA12: & polyamide 12 \\
\hline PE: & polyethylene \\
\hline PEAA: & $\begin{array}{l}\text { high density polyethylene-grafted-acrylic } \\
\text { acid }\end{array}$ \\
\hline PE-g-MA: & maleic anhydride grafted polyethylene \\
\hline PMMA: & poly(methyl methacrylate) \\
\hline POE- $g$-MA: & $\begin{array}{l}\text { maleic anhydride polyethylene octane } \\
\text { elastomer }\end{array}$ \\
\hline PP: & polypropylene \\
\hline PP-g-MAH: & maleic anhydride grafted polypropylene \\
\hline PPO: & poly(phenylene oxide) \\
\hline PS: & polystyrene \\
\hline
\end{tabular}

SEBS: $\quad$ styrene-ethylene/butylenes-styrene tri-

SEBS-g-MA: maleated styrene-ethylene butylenesstyrene

SMA: $\quad$ styrene-maleic anhydride copolymer

S-MMT: $\quad$ stearylamine modified MMT (S-MMT)

SWCNT: $\quad$ single-walled carbon nanotube

SWCNTs-COOH: carboxylic acid functionalized single walled carbon nanotubes

TEM: $\quad$ transmission electron microscopy

TLCP: $\quad$ thermotropic liquid crystalline polymer

XRD: X-ray diffraction

\section{Acknowledgements}

The authors would like to thank the Universiti Sains Malaysia for the Research University Grant (grant number: $814070,814199,814132$ ) and Ministry of Higher Education (Malaysia) for the FRGS Grant (grant number: 6071260) and ERGS grant (grant number: 6730084). We sincerely thank Professor Karger-Kocsis for his professional advice and knowledge sharing in the research and development of polymer blend nanocomposites. We also thank Prof. Azman Hassan, Professor Takeichi, Dr. Mat Uzir, Dr. Kusmono for their valuable research collaboration works and contributions.

\section{References}

[1] Chow W. S., Mohd Ishak Z. A., Karger-Kocsis J., Apostolov A. A., Ishiaku U. S.: Compatibilizing effect of maleated polypropylene on the mechanical properties and morphology of injection molded polyamide 6/ polypropylene/organoclay nanocomposites. Polymer, 44, 7427-7440 (2003).

DOI: $10.1016 /$ j.polymer.2003.09.006

[2] Erdmann E., Dias M. L., Pita V. J. R. R., Destéfanis H., Monasterio F., Acosta D.: Characterization of HDPE /polyamide 6/nanocomposites using scanning-and transmission electron microscopy. Macromolecular Symposia, 258, 82-89 (2007).

DOI: $10.1002 /$ masy.200751209

[3] Taghizadeh E., Naderi G., Razavi-Nouri M.: Effects of organoclay on the mechanical properties and microstructure of PA6/ECO blend. Polymer Testing, 30, 327-334 (2011).

DOI: 10.1016/j.polymertesting.2011.01.007

[4] Liu X-Q., Yang W., Xie B-H., Yang M-B.: Influence of multiwall carbon nanotubes on the morphology, melting, crystallization and mechanical properties of polyamide 6/acrylonitrile-butadiene-styrene blends. Materials and Design, 34, 355-362 (2012).

DOI: $10.1016 /$ j.matdes.2011.08.028

[5] Ray S. S., Okamoto M.: Polymer/layered silicate nanocomposites: A review from preparation to processing. Progress in Polymer Science, 28, 1539-1641 (2003). DOI: $10.1016 / j$.progpolymsci.2003.08.002 
[6] Chow W. S., Mohd Ishak Z. A.: Mechanical, morphological and rheological properties of polyamide 6/ organo-montmorillonite nanocomposites. Express Polymer Letters, 1, 77-83 (2007).

DOI: $10.3144 /$ expresspolymlett.2007.14

[7] Kim G-M., Lee D-H., Hoffmann B., Kressler J., Stöppelmann G.: Influence of nanofillers on the deformation process in layered silicate/polyamide-12 nanocomposites. Polymer, 42, 1095-1100 (2001).

DOI: 10.1016/S0032-3861(00)00468-7

[8] Liu X., Wu Q., Berglund L. A.: Polymorphism in polyamide 66/clay nanocomposites. Polymer, 43, 49674972 (2002).

DOI: $10.1016 / \mathrm{S} 0032-3861(02) 00331-2$

[9] Lonjon A., Caffrey I., Carponcin D., Dantras E., Lacabanne C.: High electrically conductive composites of Polyamide 11 filled with silver nanowires: Nanocomposites processing, mechanical and electrical analysis. Journal of Non-Crystalline Solids, 376, 199-204 (2013). DOI: $10.1016 /$ j.jnoncrysol.2013.05.020

[10] Li Y., Shimizu H.: Co-continuous polyamide 6 (PA6)/ acrylonitrile-butadiene-styrene (ABS) nanocomposites. Macromolecular Rapid Communications, 26, 710 715 (2005).

DOI: $10.1002 /$ marc. 200400654

[11] Dayma N., Satapathy B. K.: Microstructural correlations to micromechanical properties of polyamide-6/ low density polyethylene-grafted-maleic anhydride/ nanoclay ternary nanocomposites. Materials and Design, 33, 510-522 (2012).

DOI: $10.1016 /$ j.matdes.2011.04.057

[12] Chow W. S., Mohd Ishak Z. A., Ishiaku U. S., KargerKocsis J., Apostolov A. A.: The effect of organoclay on the mechanical properties and morphology of injectionmolded polyamide 6/polypropylene nanocomposites. Journal of Applied Polymer Science, 91, 175-189 (2004).

DOI: $10.1002 / a p p .13244$

[13] Chow W. S., Abu Bakar A., Mohd Ishak Z. A., KargerKocsis J., Ishiaku U. S.: Effect of maleic anhydridegrafted ethylene-propylene rubber on the mechanical, rheological and morphological properties of organoclay reinforced polyamide 6/polypropylene nanocomposites. European Polymer Journal, 41, 687-696 (2005). DOI: 10.1016/j.eurpolymj.2004.10.041

[14] Wahit M. U., Hassan A., Mohd Ishak Z. A., Abu Bakar A.: The effect of polyethylene-octene elastomer on the morphological and mechanical properties of polyamide 6/polypropylene nanocomposites. Polymer and Polymer Composites, 13, 795-805 (2005).

[15] Hassan A., Othman N., Wahit M. U., Wei L. J., Rachmat A. R., Mohd Ishak Z. A.: Maleic anhydride polyethylene octene elastomer toughened polyamide 6/ polypropylene nanocomposites: Mechanical and morphological properties. Macromolecular Symposia, 239, 182-191 (2006).

DOI: $10.1002 /$ masy.200690095
[16] Kusmono, Mohd Ishak Z. A., Chow W. S., Takeichi T., Rochmadi: Influence of SEBS- $g$-MA on morphology, mechanical, and thermal properties of PA6/PP/organoclay nanocomposites. European Polymer Journal, 44, 1023-1039 (2008).

DOI: 10.1016/j.eurpolymj.2008.01.019

[17] Kusmono, Mohd Ishak Z. A., Chow W. S., Takeichi T., Rochmadi: Compatibilizing effect of SEBS- $g$-MA on the mechanical properties of different types of OMMT filled polyamide 6/polypropylene nanocomposites. Composites Part A: Applied Science and Manufacturing, 39, 1802-1814 (2008).

DOI: 10.1016/j.compositesa.2008.08.009

[18] Kusmono, Mohd Ishak Z. A., Chow W. S., Takeichi T., Rochmadi: Enhancement of properties of PA6/PP nanocomposites via organic modification and compatibilization. Express Polymer Letters, 2, 655-664 (2008). DOI: $10.3144 /$ expresspolymlett.2008.78

[19] Varley R. J., Groth A. M., Leong K. H.: Preparation and characterisation of polyamide-polyimide organoclay nanocomposites. Polymer International, 57, 618-625 (2008). DOI: $10.1002 /$ pi.2385

[20] Zhang B., Wong J. S-P., Yam R. C-M., Li R. K-Y.: Enhanced wear performance of nylon 6/organoclay nanocomposite by blending with a thermotropic liquid crystalline polymer. Polymer Engineering and Science, 50, 900-910 (2010).

DOI: $10.1002 /$ pen. 21607

[21] Chen J., Wu W., Chen C., He S.: Toughened nylon66/ nylon6 ternary nanocomposites by elastomers. Journal of Applied Polymer Science, 115, 588-598 (2010).

DOI: 10.1002/app.30989

[22] Bose S., Bhattacharyya A. R., Kulkarni A. R., Pötschke P.: Electrical, rheological and morphological studies in co-continuous blends of polyamide 6 and acrylonitrile-butadiene-styrene with multiwall carbon nanotubes prepared by melt blending. Composites Science and Technology, 69, 365-372 (2009). DOI: $10.1016 /$ j.compscitech.2008.10.024

[23] Malmir S., Razavi Aghjeh M. K., Hemmati M., Ahmadi Tehrani R.: Relationship between morphology and rheology of PA/PE/clay blend nanocomposites. I. PA matrix. Journal of Applied Polymer Science, 125, E503E514 (2012).

DOI: $10.1002 / a p p .36439$

[24] Khoshkava V., Dini M., Nazockdast H.: Study on morphology and microstructure development of PA6/LDPE/ organoclay nanocomposites. Journal of Applied Polymer Science, 125, E197-E203 (2012).

DOI: 10.1002/app.33970

[25] Ogunniran E. S., Sadiku R., Ray S. S., Luruli N.: Morphology and thermal properties of compatibilized PA12/ PP blends with boehmite alumina nanofiller inclusions. Macromolecular Materials and Engineering, 297, 627-638 (2012).

DOI: $10.1002 /$ mame. 201100254 
[26] Madhukar K., Sainath A. V. S., Sanjeeva Rao B., Suresh Kumar D., Bikshamaiah N., Srinivas Y., Mohan Babu N., Ashok B.: Role of carboxylic acid functionalized single walled carbon nanotubes in polyamide 6/poly (methyl methacrylate) blend. Polymer Engineering and Science, 53, 397-402 (2013).

DOI: $10.1002 /$ pen.23272

[27] Lu C., Gao X-P., Yang D., Cao Q-Q., Huang X-H., Liu J-C., Zhang Y-Q.: Flame retardancy of polystyrene/ nylon- 6 blends with dispersion of clay at the interface. Polymer Degradation and Stability, 107, 10-20 (2014). DOI: 10.1016/j.polymdegradstab.2014.04.028

[28] Parpaite T., Otazaghine B., Taguet A., Sonnier R., Caro A. S., Lopez-Cuesta J. M.: Incorporation of modified Stöber silica nanoparticles in polystyrene/polyamide-6 blends: Coalescence inhibition and modification of the thermal degradation via controlled dispersion at the interface. Polymer, 55, 2704-2715 (2014).

DOI: $10.1016 /$ j.polymer.2014.04.016

[29] Tjong S. C., Bao S. P.: Impact fracture toughness of polyamide-6/montmorillonite nanocomposites toughened with a maleated styrene/ethylene butylene/styrene elastomer. Journal of Polymer Science Part B: Polymer Physics, 43, 585-595 (2005).

DOI: $10.1002 /$ polb. 20360

[30] Ahn Y-C., Paul D. R.: Rubber toughening of nylon 6 nanocomposites. Polymer, 47, 2830-2838 (2006). DOI: $10.1016 /$ j.polymer.2006.02.074

[31] Baldi F., Bignotti F., Tieghi G., Riccò T.: Rubber toughening of polyamide 6/organoclay nanocomposites obtained by melt blending. Journal of Applied Polymer Science, 99, 3406-3416 (2006).

DOI: 10.1002/app.22955

[32] Dong W., Zhang X., Liu Y., Wang Q., Gui H., Gao J., Song Z., Lai J., Huang F., Qiao J.: Flame retardant nanocomposites of polyamide 6/clay/silicone rubber with high toughness and good flowability. Polymer, 47, 6874-6879 (2006).

DOI: $10.1016 /$ j.polymer.2006.07.038

[33] Farahani R. D., Ahmad Ramazani S. A.: Melt preparation and investigation of properties of toughened polyamide 66 with SEBS- $g$-MA and their nanocomposites. Materials and Design, 29, 105-111 (2008).

DOI: $10.1016 /$ j.matdes.2006.11.018

[34] García-López D., López-Quintana S., GobernadoMitre I., Merino J. C., Pastor J. M.: Study of melt compounding conditions and characterization of polyamide 6/ metallocene ethylene-polypropylene-diene copolymer/maleated ethylene-polypropylene-diene copolymer blends reinforced with layered silicates. Polymer Engineering and Science, 47, 1033-1039 (2007). DOI: $10.1002 /$ pen.20782

[35] Wang K., Wang C., Li J., Su J., Zhang Q., Du R., Fu Q.: Effects of clay on phase morphology and mechanical properties in polyamide 6/EPDM-g-MA/organoclay ternary nanocomposites. Polymer, 48, 21442154 (2007).

DOI: $10.1016 /$ j.polymer.2007.01.070
[36] González I., Eguiazábal J. I., Nazábal J.: Compatibilization level effects on the structure and mechanical properties of rubber-modified polyamide-6/clay nanocomposites. Journal of Polymer Science Part B: Polymer Physics, 43, 3611-3620 (2005). DOI: $10.1002 /$ polb.20663

[37] González I., Eguiazábal J. I., Nazábal J.: Rubbertoughened polyamide 6/clay nanocomposites. Composites Science and Technology, 66, 1833-1843 (2006). DOI: 10.1016/j.compscitech.2005.10.008

[38] González I., Eguiazábal J. I., Nazábal J.: Effects of the processing sequence and critical interparticle distance in PA6-clay/mSEBS nanocomposites. European Polymer Journal, 44, 287-299 (2008).

DOI: 10.1016/j.eurpolymj.2007.11.027

[39] Zhang L., Wan C., Zhang Y.: Investigation on morphology and mechanical properties of polyamide 6/ maleated ethylene-propylene-diene rubber/organoclay composites. Polymer Engineering and Science, 49, 209-216 (2009).

DOI: 10.1002/pen.21201

[40] Prasath Balamurugan G., Maiti S. N.: Effects of nanotalc inclusion on mechanical, microstructural, melt shear rheological, and crystallization behavior of polyamide 6-based binary and ternary nanocomposites. Polymer Engineering and Science, 50, 1978-1993 (2010). DOI: $10.1002 /$ pen.21724

[41] Yoo Y., Tiwari R. R., Yoo Y-T., Paul D. R.: Effect of organoclay structure and mixing protocol on the toughening of amorphous polyamide/elastomer blends. Polymer, 51, 4907-4915 (2010). DOI: $10.1016 /$ j.polymer.2010.08.036

[42] Zhang B., Wong J. S-P., Shi D., Yam R. C-M., Li R. KY.: Investigation on the mechanical performances of ternary nylon 6/SEBS elastomer/nano- $\mathrm{SiO}_{2}$ hybrid composites with controlled morphology. Journal of Applied Polymer Science, 115, 469-479 (2010). DOI: $10.1002 / a p p .30185$

[43] Liao C. Z., Tjong S. C.: Mechanical and thermal behaviour of polyamide $6 /$ silicon carbide nanocomposites toughened with maleated styrene-ethylenebutylene-styrene elastomer. Fatigue and Fracture of Engineering Materials and Structures, 35, 56-63 (2011).

DOI: $10.1111 /$ j.1460-2695.2011.01561.X

[44] Jahromi A. E., Arefazar A., Jazani O. M., Sari M. G., Saeb M. R., Salehil M.: Taguchi-based analysis of polyamide 6/acrylonitrile-butadiene rubber/nanoclay nanocomposites: The role of processing variables. Journal of Applied Polymer Science, 130, 820-828 (2013). DOI: 10.1002/app.39191

[45] Gallego R., García-López D., Merino J. C., Pastor J. M.: How do the shape of clay and type of modifier affect properties of polymer blends? Journal of Applied Polymer Science, 127, 3009-3016 (2013).

DOI: 10.1002/app.37979 
[46] Zhou L., Wan Y., Chen X., Sun S., Zhou C.: Toughening of PA6 nanocomposites by reactive acrylonitrilebutadiene-styrene core-shell rubber particles. Polymer Composites, 35, 864-871 (2014).

DOI: $10.1002 /$ pc. 22730

[47] Rhim J-W., Park H-M., Ha C-S.: Bio-nanocomposites for food packaging applications. Progress in Polymer Science, 38, 1629-1652 (2013).

DOI: 10.1016/j.progpolymsci.2013.05.008

[48] Xiang F., Shi Y., Li X., Huang T., Chen C., Peng Y., Wang Y.: Cocontinuous morphology of immiscible high density polyethylene/polyamide 6 blend induced by multiwalled carbon nanotubes network. European Polymer Journal, 48, 350-361 (2012).

DOI: 10.1016/j.eurpolymj.2011.11.013

[49] Nesterov A. E., Lipatov Y. S.: Compatibilizing effect of a filler in binary polymer mixtures. Polymer, 40, 13471349 (1999).

DOI: $10.1016 / \mathrm{S} 0032-3861(98) 00277-8$

[50] Zou H., Zhang Q., Tan H., Wang K., Du R., Fu Q.: Clay locked phase morphology in the PPS/PA66/clay blends during compounding in an internal mixer. Polymer, 47, 6-11 (2006). DOI: $10.1016 /$ j.polymer.2005.11.031

[51] Zou H., Wang K., Zhang Q., Fu Q.: A change of phase morphology in poly ( $p$-phenylene sulfide)/polyamide 66 blends induced by adding multi-walled carbon nanotubes. Polymer, 47, 7821-7826 (2006). DOI: 10.1016/j.polymer.2006.09.008

[52] Cai X., Li B., Pan Y., Wu G.: Morphology evolution of immiscible polymer blends as directed by nanoparticle self-agglomeration. Polymer, 53, 259-266 (2012).

DOI: $10.1016 /$ j.polymer.2011.11.032

[53] Filippone G., Acierno D.: Altering the onset of co-continuity in nanocomposite immiscible blends by acting on the melt-compounding procedure. Journal of Applied Polymer Science, 122, 3712-3719 (2011).

DOI: 10.1002/app.34785

[54] Entezam M., Khonakdar H. A., Yousefi A. A., Jafari S. H., Wagenknecht U., Heinrich G.: Dynamic and transient shear start-up flow experiments for analyzing nanoclay localization in PP/PET blends: Correlation with microstructure. Macromolecular Materials and Engineering, 298, 113-126 (2013).

DOI: $10.1002 /$ mame.201100435

[55] Bhadane P. A., Champagne M. F., Huneault M. A., Tofan F., Favis B. D.: Continuity development in polymer blends of very low interfacial tension. Polymer, 47, 2760-2771 (2006).

DOI: $10.1016 /$ j.polymer.2006.01.065

[56] Ramic A. J., Hudson S. D., Jamieson A. M., ManasZloczower I.: Temporary droplet-size hysteresis in immiscible polymer blends. Polymer, 41, 6263-6270 (2000).

DOI: 10.1016/S0032-3861(99)00845-9
[57] Périé T., Brosse A-C., Tencé-Girault S., Leibler L.: Cocontinuous nanostructured nanocomposites by reactive blending of carbon nanotube masterbatches. Polymer, 53, 984-992 (2012).

DOI: 10.1016/j.polymer.2012.01.007

[58] Kelnar I., Rotrekl J., Kotek J., Kaprálková L.: Effect of montmorillonite modification on the behaviour of polyamide/polystyrene blends. Polymer International, 57, 1281-1286 (2008).

DOI: $10.1002 /$ pi.2475

[59] Filippone G., Dintcheva N. Tz., Acierno D., La Mantia F. P.: The role of organoclay in promoting co-continuous morphology in high-density poly(ethylene)/poly (amide) 6 blends. Polymer, 49, 1312-1322 (2008). DOI: 10.1016/j.polymer.2008.01.045

[60] Filippone G., Dintcheva N. Tz., La Mantia F. P., Acierno D.: Using organoclay to promote morphology refinement and $\mathrm{co}$-continuity in high-density polyethylene/polyamide 6 blends - Effect of filler content and polymer matrix composition. Polymer, 51, 3956-3965 (2010). DOI: $10.1016 /$ j.polymer.2010.06.044

[61] Nuzzo A., Bilotti E., Peijs T., Acierno D., Filippone G.: Nanoparticle-induced co-continuity in immiscible polymer blends - A comparative study on bio-based PLAPA11 blends filled with organoclay, sepiolite, and carbon nanotubes. Polymer, 55, 4908-4919 (2014). DOI: $10.1016 /$ j.polymer.2014.07.036

[62] Nuzzo A., Coiai S., Carroccio S. C., Dintcheva N. Tz., Gambarotti C., Filippone G.: Heat-resistant fully biobased nanocomposite blends based on poly(lactic acid). Macromolecular Materials and Engineering, 299, 3140 (2014). DOI: $10.1002 / \mathrm{mame} .201300051$

[63] Chen J., Chen J-W., Chen H-M., Yang J-H., Chen C., Wang Y.: Effect of compatibilizer and clay on morphology and fracture resistance of immiscible high density polyethylene/polyamide 6 blend. Composites Part B, 54, 422-430 (2013).

DOI: 10.1016/j.compositesb.2013.06.014

[64] González I., Eguiazábal J. I., Nazabal J.: Attaining high electrical conductivity and toughness in PA6 by combined addition of MWCNT and rubber. Composites Part A: Applied Science and Manufacturing, 43, 1482-1489 (2012).

DOI: 10.1016/j.compositesa.2012.03.013

[65] Bose S., Bhattacharyya A. R., Khare R. A., Kamath S. S., Kulkarni A. R.: The role of specific interaction and selective localization of multiwall carbon nanotubes on the electrical conductivity and phase morphology of multicomponent polymer blends. Polymer Engineering and Science, 51, 1987-2000 (2011). DOI: $10.1002 /$ pen. 21998 
[66] Yan D. G., Yang G. S.: Effect of multiwalled carbon nanotubes on the morphology and electrical properties of polyamide 6/polystyrene blends prepared via successive polymerization. Journal of Applied Polymer Science, 125, E167-E174 (2012).

DOI: $10.1002 /$ app. 35680

[67] Siengchin S., Karger-Kocsis J.: Structure and creep response of toughened and nanoreinforced polyamides produced via the latex route: Effect of nanofiller type. Composites Science and Technology, 69, 677-683 (2009).

DOI: 10.1016/j.compscitech.2009.01.003

[68] Li W., Karger-Kocsis J., Schlarb A. K.: Dispersion of $\mathrm{TiO}_{2}$ particles in PET/PP/TiO 2 and PET/PP/PP-g-MA/ $\mathrm{TiO}_{2}$ composites prepared with different blending procedures. Macromolecular Materials and Engineering, 294, 582-589 (2009).

DOI: $10.1002 /$ mame.200900123

[69] Wang L., Guo Z-X., Yu J.: Effect of compounding sequence on the morphology of organoclay-filled PA6/ PP/MAPP blends. Journal of Applied Polymer Science, 120, 2261-2270 (2011).

DOI: $10.1002 / a p p .33450$

[70] Naderi G., Razavi-Nouri M., Taghizadeh E., Lafleur P. G., Dubois C.: Preparation of thermoplastic elastomer nanocomposites based on polyamide-6/polyepichlorohydrin-co-ethylene oxide. Polymer Engineering and Science, 51, 278-284 (2011).

DOI: $10.1002 /$ pen. 21824

[71] Oliveira A. D., Larocca N. M., Paul D. R., Pessan L. A.: Effects of mixing protocol on the performance of nanocomposites based on polyamide 6/acrylonitrile-butadiene-styrene blends. Polymer Engineering and Science, 52, 1909-1919 (2012).

DOI: $10.1002 /$ pen.23152

[72] Zhang M., Lin B., Sundararaj U.: Effects of processing sequence on clay dispersion, phase morphology, and thermal and rheological behaviors of PA6-HDPE-clay nanocomposites. Journal of Applied Polymer Science, 125, E714-E724 (2012).

DOI: $10.1002 / a p p .36692$

[73] Dasari A., Yu Z-Z., Mai Y-W.: Effect of blending sequence on microstructure of ternary nanocomposites. Polymer, 46, 5986-5991 (2005). DOI: $10.1016 /$ j.polymer.2005.05.145

[74] Yang J., Sun L., Xiang S., He J., Gu L., Zhong M.: Influence of organoclay and preparation technique on the morphology of polyamide 6/polystyrene/organoclay nanocomposites. Journal of Applied Polymer Science, 110, 276-282 (2008).

DOI: $10.1002 / a p p .28178$

[75] Ozkoc G., Bayram G., Tiesnitsch J.: Microcompounding of organoclay-ABS/PA6 blend-based nanocomposites. Polymer Composites, 29, 345-356 (2008). DOI: $10.1002 /$ pc.20392
[76] Chow W. S.: Cyclic extrusion of poly(butylene terephthalate)/organo-montmorillonite nanocomposites: Thermal and mechanical retention properties. Journal of Applied Polymer Science, 110, 1642-1648 (2008). DOI: 10.1002/app.28804

[77] Scaffaro R., Botta L., Mistretta M. C., La Mantia F. P.: Processing - morphology - property relationships of polyamide 6/polyethylene blend-clay nanocomposites. Express Polymer Letters, 7, 873-884 (2013).

DOI: 10.3144 /expresspolymlett.2013.84

[78] Vaia R. A., Ishii H., Giannelis E. P.: Synthesis and properties of two-dimensional nanostructures by direct intercalation of polymer melts in layered silicates. Chemistry of Materials, 5, 1694-1696 (1993).

DOI: $10.1021 / \mathrm{cm} 00036 \mathrm{a} 004$

[79] Giannelis E. P.: Polymer layered silicate nanocomposites. Advanced Materials, 8, 29-35 (1996).

DOI: $10.1002 /$ adma.19960080104

[80] Usuki A., Kojima Y., Kawasumi M., Okada A., Fukushima Y., Kurauchi T., Kamigaito O.: Synthesis of nylon 6-clay hybrid. Journal of Materials Research, 8, 1179-1184 (1993). DOI: $10.1557 /$ JMR.1993.1179

[81] Scaffaro R., Mistretta M. C., La Mantia F. P.: Compatibilized polyamide 6/polyethylene blend-clay nanocomposites: Effect of the degradation and stabilization of the clay modifier. Polymer Degradation and Stability, 93, 1267-1274 (2008).

DOI: $10.1016 /$ j.polymdegradstab.2008.04.008

[82] Fang Z., Xu Y., Tong L.: Effect of clay on the morphology of binary blends of polyamide 6 with high density polyethylene and HDPE-graft-acrylic acid. Polymer Engineering and Science, 47, 551-559 (2007). DOI: $10.1002 /$ pen.20675

[83] Mallick S., Khatua B. B.: Morphology and properties of nylon6 and high density polyethylene blends in absence and presence of nanoclay. Journal of Applied Polymer Science, 121, 359-368 (2011).

DOI: 10.1002/app.33580

[84] Chow W. S., Mohd Ishak Z. A., Karger-Kocsis J.: Morphological and rheological properties of polyamide 6/ poly(propylene)/organoclay nanocomposites. Macromolecular Materials and Engineering, 290, 122-127 (2005). DOI: 10.1002/mame.200400269

[85] Mojarrad A., Jahani Y., Barikani M.: Influence of nanoclay on the rheological properties of polyamide 6/ acrylonitrile butadiene styrene nanocomposites. Journal of Applied Polymer Science, 125, E571-E582 (2012). DOI: $10.1002 / a p p .34092$

[86] Kusmono, Mohd Ishak Z. A., Chow W. S., Takeichi T., Rochmadi: Effect of clay modification on the morphological, mechanical, and thermal properties of polyamide 6/polypropylene/montmorillonite nanocomposites. Polymer Composites, 31, 1156-1167 (2010). DOI: $10.1002 /$ pc.20902 
[87] Chow W. S., Abu Bakar A., Mohd Ishak Z. A.: Water absorption and hygrothermal aging study on organomontmorillonite reinforced polyamide 6/polypropylene nanocomposites. Journal of Applied Polymer Science, 98, 780-790 (2005).

DOI: $10.1002 / a p p .22172$

[88] Dayma N., Satapathya B. K., Patnaik A.: Structural correlations to sliding wear performance of PA-6/PP- $g$-MA/ nanoclay ternary nanocomposites. Wear, 271, 827-836 (2011). DOI: $10.1016 /$ j.wear.2011.03.008

[89] Hassani A. J., Mohd Ishak Z. A., Mohamed A. R.: Preparation and characterization of polyamide 6 nanocomposites using MWCNTs based on bimetallic Co-Mo/ $\mathrm{MgO}$ catalyst. Express Polymer Letters, 8, 177-186 (2014).

DOI: $10.3144 /$ expresspolymlett.2014.21

[90] Shrivastava N. K., Maiti S., Suin S., Khatua B. B.: Influence of selective dispersion of MWCNT on electrical percolation of in-situ polymerized high-impact polystyrene/MWCNT nanocomposites. Express Polymer Letters, 8, 15-29 (2014).

DOI: $10.3144 /$ expresspolymlett.2014.3

[91] Zhang L., Wan C., Zhang Y.: Morphology and electrical properties of polyamide 6/polypropylene/multiwalled carbon nanotubes composites. Composites Science and Technology, 69, 2212-2217 (2009).

DOI: 10.1016/j.compscitech.2009.06.005

[92] Ou B., Li D., Liu Y.: Compatibilizing effect of maleated polypropylene on the mechanical properties of injection molded polypropylene/polyamide 6/functionalized$\mathrm{TiO}_{2}$ nanocomposites. Composites Science and Technology, 69, 421-426 (2009).

DOI: 10.1016/j.compscitech.2008.11.010

[93] Karger-Kocsis J., Gryshchuk O., Fröhlich J., Mülhaupt R.: Interpenetrating vinylester/epoxy resins modified with organophilic layered silicates. Composites Science and Technology, 63, 2045-2054 (2003).

DOI: 10.1016/S0266-3538(03)00110-6

[94] Chow W. S., Mohd Ishak Z. A., Karger-Kocsis J.: Atomic force microscopy study on blend morphology and clay dispersion in polyamide-6/polypropylene/ organoclay systems. Journal of Polymer Science Part B: Polymer Physics, 43, 1198-1204 (2005).

DOI: $10.1002 /$ polb.20408

[95] Covas J. A., Almeida M. F., Machado A. V., Larocca N. M., Pessan L. A.: Nanoclays dispersion in a PA6/PP blend by twin screw compounding. Macromolecular Symposia, 301, 55-62 (2011).

DOI: $10.1002 /$ masy.201150308

[96] Zhang L., Wan C., Zhang Y.: Investigation on the multiwalled carbon nanotubes reinforced polyamide 6/polypropylene composites. Polymer Engineering and Science, 49, 1909-1917 (2009).

DOI: $10.1002 /$ pen. 21428
[97] Li W., Karger-Kocsis J., Thomann R.: Compatibilization effect of $\mathrm{TiO}_{2}$ nanoparticles on the phase structure of $\mathrm{PET} / \mathrm{PP} / \mathrm{TiO}_{2}$ nanocomposites. Journal of Polymer Science Part B: Polymer Physics, 47, 1616-1624 (2009). DOI: $10.1002 /$ polb.21752

[98] As'habi L., Jafari S. H., Khonakdar H. A., Boldt R., Wagenknecht U., Heinrich G.: Tuning the processability, morphology and biodegradability of clay incorporated PLA/LLDPE blends via selective localization of nanoclay induced by melt mixing sequence. Express Polymer Letters, 7, 21-39 (2013). DOI: $10.3144 /$ expresspolymlett.2013.3

[99] Mallick S., Kar P., Khatua B. B.: Morphology and properties of nylon 6 and high density polyethylene blends in presence of nanoclay and PE- $g$-MA. Journal of Applied Polymer Science, 123, 1801-1811 (2012). DOI: 10.1002/app.34648

[100] Jogi B. F., Bhattacharyya A. R., Poyekar A. V., Pötschke P., Simon G. P., Kumar S.: The simultaneous addition of styrene maleic anhydride copolymer and multiwall carbon nanotubes during melt-mixing on the morphology of binary blends of polyamide 6 and acrylonitrile butadiene styrene copolymer. Polymer Engineering and Science, in press (2015).

DOI: $10.1002 /$ pen.23905

[101] Attari M., Arefazar A., Bakhshandeh G.: Mechanical and thermal properties of toughened PA6/HDPE/ SEBS- $g$-MA/clay nanocomposite. Polymer Engineering and Science, in press (2015).

DOI: $10.1002 /$ pen.23866

[102] Kusmono, Mohd Ishak Z. A., Chow W. S., Takeichi T., Rochmadi: Effects of compatibilizers and testing speeds on the mechanical properties of organophilic montmorillonite filled polyamide 6/polypropylene nanocomposites. Polymer Engineering and Science, 50, 1493-1504 (2010).

DOI: $10.1002 /$ pen.21622

[103] Kelnar I., Khunová V., Kotek J., Kaprálková L.: Effect of clay treatment on structure and mechanical behavior of elastomer-containing polyamide 6 nanocomposite. Polymer, 48, 5332-5339 (2007).

DOI: $10.1016 /$ j.polymer.2007.06.062

[104] Kelnar I., Rotrek1 J., Kotek J., Kaprálková L., Hromádková J.: Effect of montmorillonite on structure and properties of nanocomposite with PA6/PS/elastomer matrix. European Polymer Journal, 45, 2760-2766 (2009).

DOI: 10.1016/j.eurpolymj.2009.06.024

[105] Siengchin S., Karger-Kocsis J.: Mechanical and stress relaxation behavior of Santoprene ${ }^{\circledR}$ thermoplastic elastomer/boehmite alumina nanocomposites produced by water-mediated and direct melt compounding. Composites Part A: Applied Science and Manufacturing, 41, 768-773 (2010). DOI: $10.1016 /$ j.compositesa.2010.02.009 
[106] Prashantha K., Lacrampe M. F., Krawczak P.: Processing and characterization of halloysite nanotubes filled polypropylene nanocomposites based on a masterbatch route: Effect of halloysites treatment on structural and mechanical properties. Express Polymer Letters, 5, 295-307 (2011).

DOI: 10.3144/expresspolymlett.2011.30

[107] Prashantha K., Schmitt H., Lacrampe M. F., Krawczak P.: Mechanical behaviour and essential work of fracture of halloysite nanotubes filled polyamide 6 nanocomposites. Composites Science and Technology, 71, 1859-1866 (2011).

DOI: 10.1016/j.compscitech.2011.08.019

[108] Pedrazzoli D., Pegoretti A., Thomann R., Kristóf J., Karger-Kocsis J.: Toughening linear low-density polyethylene with halloysite nanotubes. Polymer Composites, in press (2015).

DOI: $10.1002 / p c .23006$

[109] Sridhar V., Lee I., Chun H. H., Park H.: Graphene reinforced biodegradable poly(3-hydroxybutyrateco-4-hydroxybutyrate) nano-composites. Express Polymer Letters, 7, 320-328 (2013).

DOI: 10.3144/expresspolymlett.2013.29

[110] Gopiraman M., Fujimori K., Zeeshan K., Kim B. S., Kim I. S.: Structural and mechanical properties of cellulose acetate/graphene hybrid nanofibers: Spectroscopic investigations. Express Polymer Letters, 7, 554-563 (2013).

DOI: $10.3144 /$ expresspolymlett.2013.52
[111] Bhattacharyya A., Chen S., Zhu M.: Graphene reinforced ultra high molecular weight polyethylene with improved tensile strength and creep resistance properties. Express Polymer Letters, 8, 74-84 (2014). DOI: $10.3144 /$ expresspolymlett.2014.10

[112] Chang K. C., Hsu C. H., Lu H. I., Ji W. F., Chang C. H., Li W. Y., Chuang T. L., Yeh J. M., Liu W. R., Tsai M. H.: Advanced anticorrosive coatings prepared from electroactive polyimide/graphene nanocomposites with synergistic effects of redox catalytic capability and gas barrier properties. Express Polymer Letters, 8, 243-255 (2014).

DOI: $10.3144 /$ expresspolymlett.2014.28

[113] Wu C. M., Yu S. A., Lin S. L.: Graphene modified electrospun poly(vinyl alcohol) nanofibrous membranes for glucose oxidase immobilization. Express Polymer Letters, 8, 565-573 (2014).

DOI: $10.3144 /$ expresspolymlett.2014.60

[114] Seppälä J., Luong N. D.: Chemical modification of graphene for functional polymer nanocomposites. Express Polymer Letters, 8, 373 (2014).

DOI: $10.3144 /$ expresspolymlett.2014.41 